\title{
Insediamenti templari sulla costa adriatica orientale e relazioni con il versante Adriatico occidentale
}

La presenza dei Templari in territorio croato in generale, e in quello dalmata e istriano nella fattispecie, è da attribuire al ruolo svolto da questa regione di transito verso la Terrasanta, sia via mare che via terra. Molto importanti furono gli insediamenti nei centri costieri, in primo luogo il porto di Senj, per i collegamenti con le città adriatiche italiane. Particolarmente favorevoli a Templari furono i sovrani del regno di Ungheria-Croazia che presero sotto la propria protezione l'Ordine con l'elargizione di una pluralità di donazioni, non sono beni, ma interi feudi o città. Da parte loro, i Templari furono sempre uomini di fiducia sia della dinastia Árpád che di quella Angioina. Principale centro templare sulla costa dalmata fu la domus di Vrana, già monastero benedettino trasformato in fortezza dai cavalieri. Purtroppo i rapporti con i Templari e gli abitanti dei luoghi in cui erano insediati non furono sempre buoni, basti pensare alle difficoltà incontrate a Senj, Klis e Šibenik che costrinsero l'Ordine ad abbandonare tali località con grave danno economico soprattutto per la perdita di Senj che fruttava notevoli entrate per i diritti sull'ingresso delle navi nel porto. Dopo aver trattato della presenza templare nella zona litoranea croata e in Istria si è proceduto a esaminare le relazioni tra le due coste dell'Adriatico nelle quali sono coinvolti i Templari, individuando tre categorie. La prima tipologia comprende le relazioni e gli scambi di tipo economico e commerciale come il trasporto di frumento dalla Puglia a Zara, la spedizione di legumi nella provincia di Ungheria, il ricorso da parte dei Templari pugliesi ad armatori dalmati. La seconda categoria riguarda $\mathrm{i}$ rapporti tra gli insediamenti templari del litorale croato e istriano e la Repubblica di Venezia; mentre l'ultima prende in esame le relazioni relative ai cavalieri templari nel loro trasferimento da una mansione all'altra per mobilità o nello svolgimento di attività diplomatica soprattutto a seguito dell'ascesa della dinastia angioina, che già governava l'Italia meridionale, al trono di Ungheria-Croazia.

\section{Introduzione}

Il territorio tra le Alpi e l'Adriatico, diviso tra l'Impero e il regno d'UngheriaCroazia, in epoca medievale fu un'area geografica molto interessata al transito di pellegrini e crociati, provenienti principalmente dall'Europa settentrionale, diretti in Terrasanta tanto via mare, con l'utilizzo dei porti, e tanto via terra, impiegando 
la viabilità ereditata dall'epoca romana. ${ }^{1}$ Sotto questo punto di vista essa presenta parecchie analogie con la Puglia e la resero di particolare interesse per gli Ordini militari, tra i quali i Templari, con la creazione di propri insediamenti e di strutture ospitaliere per l'accoglienza dei pellegrini. L'attuale Dalmazia costituiva lo sbocco al mare del regno ungaro-croato e le fondazioni templari di questa regione rientravano nella provincia di Ungheria. Al contrario degli Ospitalieri, il centro principale dei Templari nel regno fu in Croazia. ${ }^{2}$ Gli insediamenti ${ }^{3}$ in tale regione si concentrarono sulla fascia costiera in modo da mantenersi in collegamento con le fondazioni della penisola italiana e con la Terrasanta per poi penetrare nelle zone interne. ${ }^{4}$ Tra le motivazioni dello stanziamento, accanto alla viabilità e ai porti, va annoverato anche lo sfruttamento della terra. ${ }^{5}$ Le domus costiere nella Croazia medievale, spesso città fortificate (castra), consentirono anche una buona comunicazione con le località portuali pugliesi come Bari, Brindisi e Barletta ove avevano sede le fondazioni templari $;{ }^{6} 1$ 'unico insediamento documentato nella penisola istriana fu San Michele di Leme ottenuto da Templari solo all'inizio del XIV secolo. Particolarmente significative furono le relazioni tra le due coste dell'Adriatico che videro coinvolti i cavalieri templari; molto spesso si trattava di rapporti di natura economica, come ad esempio le spedizioni di derrate alimentari dalla Puglia agli insediamenti dalmati o il noleggio da parte dei Templari pugliesi di imbarcazioni di armatori dalmati. Altre relazioni riguardarono invece la Repubblica di Venezia, geograficamente vicina ai territori dalmati e istriani, nonché potenza egemone nel mare Adriatico. Gli scambi non riguardarono solo le merci o i beni, ma anche le persone, in particolare i cavalieri che si spostavano per incarichi all'interno dell'Ordine o per svolgere missioni diplomatiche da un versante all'altro dell'Adriatico.

Esiste oramai una consolidata letteratura sulla presenza dell'Ordine Templare nel regno ungaro-croato in generale - e sul litorale croato in particolare - e sulle principali precettorie documentate in tale territorio che inizia a partire dal XIX secolo. Una buona rassegna storiografica sulla presenza degli Ordini militari si trova in un lavoro di Hunyadi. ${ }^{7}$ Limitando l'attenzione ai soli insediamenti templari e all'ambito geografico oggetto di studio, il primo contributo è quello di Kuku-

\footnotetext{
KOSI 2001: 125 ss.; STOPANI 2006; VANNI 2006.

2 KOSI 2001: 136.

3 Altri insediamenti si trovavano in Slavonia (Gora, Glogovnica, Saint Martin-Dugo Selo, Dubica). La maggior parte dei possedimenti erano nella regione a sud della Drava.

4 HUNYADI 2011: 197.

5 HUNYADI 2011: 183.

6 KOSI 2001: 137.

7 HUNYADI 2003.
} 
ljević Sakcinski ${ }^{8}$ pubblicato alla fine dell'Ottocento e dedicato all'insediamento di Vrana durante il periodo templare e quello giovannita; per trovare nuovi lavori bisogna attendere gli anni Settanta del XX secolo: è a questo periodo che risalgono diversi contributi tutti concentrati sulla precettoria di Vrana, degno di particolare interesse è Vrana i Templari di Kolanović, ${ }^{9}$ si segnalano anche i lavori di $\operatorname{Kos}^{10} \mathrm{e}$ Peričić ${ }^{11}$ tutti pubblicati sulla rivista della sezione di Zara dell'allora Accademia delle Scienze Jugoslava. Lo studio degli Ordini militari è ripreso nel decennio successivo da Lelia Dobronić con diversi interventi ${ }^{12}$, spesso a carattere monografico, uno dei quali in lingua inglese che fornisce una conoscenza della materia in una prospettiva internazionale. ${ }^{13}$ Hunyadi ${ }^{14}$ riconosce il merito di questa Autrice di aver corretto gli errori degli studiosi precedenti, ma sottolinea come nei suoi lavori non abbia preso in considerazione le fonti presenti o pubblicate in Ungheria. Per quanto riguarda il territorio sloveno si segnala la monografia di Kosi ${ }^{15}$ del 1995. Risale al 1999 il contributo sul castello di Sebenico pubblicato da Zelić ${ }^{16}$ nel quale agli aspetti storici si accompagnano anche quelli architettonici. Accenni alla presenza templare sulla costa dalmata si trovano in alcuni lavori sui Templari in Ungheria come quello in francese di Stossek ${ }^{17}$ del 2001 e quello in inglese di Hunyadi ${ }^{18}$ del 2011. Pochi anni prima della sua scomparsa Dobronić ${ }^{19}$ ha pubblicato nel 2003 uno studio sulla presenza templare nella città di Senj. Venendo agli anni più vicini a noi l'interesse per i Templari nell'ambito della storiografia croata risulta ancora alto con il lavoro di Matić ${ }^{20}$ che legge la storia dei cavalieri nel territorio croato in chiave economica e politica. Per quanto riguarda la penisola istriana si segnala il contributo sulle istituzioni ospitaliere gestite da Benedettini, Templari e Giovanniti di Mogorović Crljenko. ${ }^{21}$ Piuttosto frammentaria invece è la letteratura in lingua italiana sulle fondazioni templari in territorio dalmata. Si trovano brevi cenni all'interno di diversi volumi dedicati alla storia della Dalmazia a partire dal XVII secolo ${ }^{22}$ : si tratta di

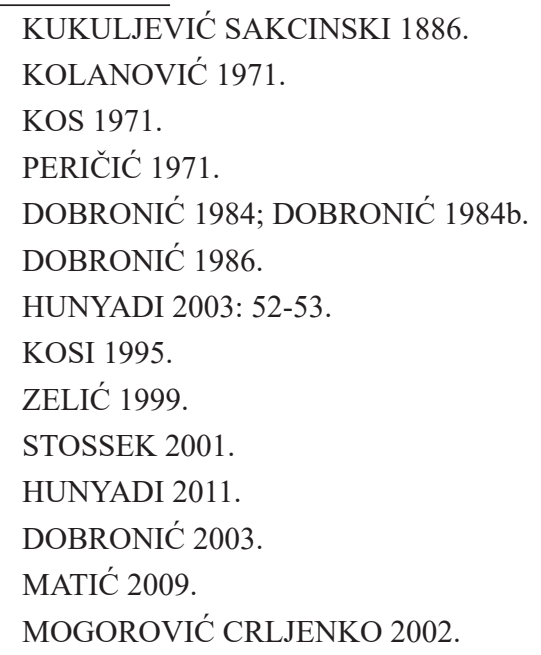


notizie isolate, quasi sempre senza indicazione della fonte, che vengono riportate quando le vicende dei Templari ebbero un riflesso sulla storia generale della Dalmazia e la cui attendibilità non è sempre verificabile. Informazioni più dettagliate sui Templari sono fornite da Valentino Lago ${ }^{23}$ sebbene anche in questa circostanza manca ogni riferimento alle fonti primarie. Qualche citazione comincia ad essere fornita dall'arcidiacono Bianchi, ${ }^{24}$ sebbene anche in tal caso sono riportate delle affermazioni sui Templari e le loro vicende e insediamenti che non sempre sono riscontrabili. Nel 1889 Ferrari-Cupilli, ${ }^{25}$ all'interno di una sua raccolta di scritti storici e letterari, dedica un capitolo ai Templari e agli Ospitalieri in Croazia che può essere considerato il primo lavoro monografico sull'argomento, trattando degli insediamenti templari e giovanniti in diversi centri dalmati. Del castello di Vrana si occupa De Benvenuti in un articolo del $1940^{26}$ pubblicato su La rivista Dalmatica nel quale vengono ripercorse le vicende storiche di questa struttura fortificata dal XI secolo sino al Cinquecento. Allo stato attuale non esistono lavori in lingua italiana che trattino in maniera dettagliata e puntuale della presenza templare nell'area dalmata attraverso l'esame critico delle fonti. Per quanto riguarda l'Istria si segnala un contributo di Pezzella ${ }^{27}$ che tuttavia può essere considerato solo un lavoro preliminare e meramente descrittivo, mancando completamente di un apparato di note.

Lo scopo di questo articolo vuole essere quello di illustrare, dopo aver presentato la situazione della presenza templare nelle aree geografiche oggetto di interesse effettuando anche dei confronti con gli insediamenti della costa pugliese, come tra XII e inizi del XIV secolo vi fu un interessante intreccio di relazioni tra gli insediamenti templari esistenti tra le due sponde del mar Adriatico, di come il loro contenuto fu estremamente vario e di come esse si intensificarono in epoca angioina potendosi attribuire, sebbene in parte, al ruolo diplomatico svolto dai Templari nell'ascesa della dinastia francese sul trono di Ungheria-Croazia.

\section{Le precettorie di Vrana e Zablace}

La prima notizia su alcuni beni posseduti dai Templari nel territorio dell'attuale Croazia risale al periodo tra il 1154 e il $1163^{28}$ con una terra a Zdela in Slavonia

\footnotetext{
22 A titolo esemplificativo: FRESCHOT 1687: 214-215, 218, 288, 302; BOMMAN 1775: 174, 245, 297; FORTIS 1774: 26-27 si sofferma sul castello di Vrana, CATTALINICH 1834: 20, 37, 251.

23 LAGO 1869; LAGO 1870: passim.

24 BIANCHI 1880: passim.

25 FERRARI-CUPILLI 1889: 173-196.

26 DE BENVENUTI 1940.

27 PEZZELLA 2004.

28 CD III: n. 8; DOBRONIĆ 1986: 433; KOSI 2001: 136.
} 
donata dal bano (governatore) di Bosnia Borić. Fejér attesta la presenza templare a Vrana al $1165^{29}$ : preceptoratus Templariorium S. Gregorii in Wrana, alias Aurana, senza tuttavia riportare la fonte. Prima del $1169^{30} \mathrm{i}$ Templari ricevettero dal papa il monastero benedettino di San Gregorio di Vrana, ${ }^{31}$ località nei pressi dell'omonimo lago, destinato a diventare un centro importante dell'Ordine nella provincia di Ungheria con funzioni anche di ospedale dei pellegrini. Nel $1169-1170$ era sorta una controversia tra i Templari di Vrana e il vescovo di Scardona Lampriudius e papa Alessandro III designava il legato apostolico Gerardo, arcivescovo di Spalato (Split), a dirimere il conflitto. ${ }^{32}$ I cavalieri ricevettero sempre credito e attenzione da parte dei sovrani ungaro-croati che spesso effettuarono donazioni a loro favore. ${ }^{33}$ Vrana $^{34}$ fu probabilmente la prima precettoria fondata nel litorale croato a seguito della donazione del monastero di San Gregorio: ${ }^{35}$ infatti nel $1194^{36}$ è attestato il precettore frate Azzo che, con il maestro provinciale Gualterio, era impegnato in una controversia con il monastero benedettino dei Santi Cosma e Damiano di Pasmano $^{37}$ (Pašman) per una questione relativa ai confini di una proprietà e a un corso d' acqua ${ }^{38}$ La discussione della causa ebbe luogo nella chiesa di San Giovanni di Tinj alla presenza dell'arcivescovo di Spalato Petrus e fu trattata da Petrus Scluradi, templariorum aduocato (si trattava di un nobile zaratino), mentre da parte del monastero benedettino e dell'abate Dominicus vi era l'avvocato Coscia di Gregorio. Dal documento si apprende come piuttosto nutrito fu il numero di coloro che assistettero alla discussione e alla stipulazione dell'atto definitivo, in esso infatti possono leggersi i nomi dei laici e degli ecclesiastici presenti, con il quale le due parti convenivano ad un accordo. Nel 1190 il monastero di Vrana

29 FEJÉR 1832: 325.

30 CD II: $n$. 120. Il documento in questione non riguarda la donazione effettuata dal papa, ma tale notizia si può arguire dal contesto. Qualche Autore del XIX secolo afferma che il priorato (sic) dei Templari a Vrana fu istituito da re Bela II nel 1138. Cfr. LAGO 1869: 166. Purtroppo non è indicata alcuna fonte, per tanto tale affermazione va presa con molta cautela, sebbene altre notizie riportate da Lago sui Templari in Dalmazia hanno trovato riscontro nei documenti. La notizia, senza indicazione della fonte, è ripresa anche da BIANCHI 1880: 361 e da ALACEVICH 1890: 93.

31 La chiesa di San Gregorio era stata donata a Gregorio VII dal re Zuonimiro nel 1076. Cfr. ALACEVICH 1890: 93 e DE BENVENUTI 1940: 50. La donazione è ricordata anche in questo documento del 1169/70: CD II: n. 120.

32 CD II: n. 120.

33 DOBRONIĆ 1986: 432-435.

34 KUKULJEVIĆ SAKCINSKI 1886; DE BENVENUTI 1940; KOLANOVIČ 1971; DOBRONIĆ 1984a: 58-59.

35 Sul periodo benedettino cfr. KUKULJEVIĆ SAKCINSKI 1886: 4-8.

36 CD II: n. 253; THEINER 1863: n. 11.

37 Per approfondimenti sulla storia di tale monastero cfr. ALACEVICH 1888-1891.

38 La vertenza si protrasse sino al 1200: cfr. CD II: n. 320, quando intervenne papa Innocenzo III. 
fu restaurato dai Templari e in quella occasione forse provvidero a fortificarlo trasformandolo in castello. ${ }^{39}$

All'inizio del XIII secolo il re Emerico (1196 - 1204) depositò il proprio argento presso la precettoria di Vrana, ritenendola evidentemente un luogo molto sicuro. ${ }^{40}$ Tale pratica ha riscontro anche in altre località, come ad esempio in Francia dove il tesoro reale era custodito nella torre del Tempio di Parigi ${ }^{41}$; oltre alla sicurezza offerta dal luogo fortificato, vi era anche un legame di tipo fiduciario con i cavalieri. Tra il $1214^{42}$ il 1220, l'arcivescovo di Spalato Bernardo consacrò l'arciprete della chiesa di Spalato Gruptius vescovo di Nona (Nin) nella chiesa di Vrana. Verso la fine degli anni venti del XIII secolo i Templari di Vrana risultano protagonisti di alcune controversie: nel $1227^{43}$ con i proprietari della chiesa di San Pietro di Bade rivendicata, assieme alle sue pertinenze, dai cavalieri (fratres domus militie Templi de Vrana) nei confronti di Forminum nepotem Petri Stresu et alios patronos ecclesie sancti Petri de Bade; i Templari videro riconosciuti i propri diritti sulla chiesa e i suoi beni fondiari (una casa, delle terre, degli orti e altri terreni coltivati) con la mediazione dell'arcivescovo di Spalato Guncellus; $;{ }^{44}$ nel $1229^{45}$ ebbero un'altra controversia con il monastero dei Santi Cosma e Damiano per il possesso di alcuni beni (super quibusdam terris vinetis et possessionibus aliis de Rogoua dictis), risolta a loro sfavore dagli arbitri (Gregorio, conte di Bribir, Guncellus, arcivescovo di Spalato, Bartolomeo, vescovo di Nona, un monaco di Thopliza, un frate ospitaliero, due domenicani e due frati minori). Ritenendosi lesi nei propri diritti si rivolsero nel $1236^{46}$ a papa

39 DE BENVENUTI 1940: 51. Tuttavia lo stesso Autore riporta che già nel XI secolo Vrana era definita castrum. Cfr. anche LAGO 1870: 367.

Thomas Archidiaconus Spalatensis 2006: 148-149.

41 DE CURZON 1888: 121-122.

42 Thomas Archidiaconus Spalatensis 2006: 156. Cfr. anche BIANCHI 1880: 207-208. Gruptius fu eletto vescovo contro il volere del Capitolo di Nona che all'unanimità aveva eletto Nicola, canonico del Capitolo di Spalato. Di fronte a tale dissidio l'arcivescovo Bernardo decise di consacrare il nuovo presule nella chiesa templare di Vrana

43 CD III: n. 240.

44 Questo presule è nominato spesso nella cronaca dell'arcidiacono Tommaso: cfr. Thomas Archidiaconus Spalatensis 2006: 166-210, 304-306. Era un nobile di origine ungherese che apparteneva all'Ordine dei crociferi ed era stato rettore della chiesa di Santo Stefano re (assumpto cruciferorum habitu factus erat rector cuiusdam ecclesie sancti Stephani regis). In Europa orientale spesso gli stessi Templari erano detti crociferi (si veda in seguito a proposito di Bojišče), ma non in questo caso: da altra fonte (una lettera del 1220 di papa Onorio III al capitolo di Spalato per la nomina ad arcivescovo di Guncellus) apprendiamo che si tratta dell'Ordine dei Crociferi di Santo Stefano, infatti è riportato: frater (Guncellus), hospitalis s. regis Stephani de ordine cruciferorum (cfr. KUKULJEVIĆ SAKCINSKI 1896: 41, n. 125). Si trattava di un Ordine religioso-militare con finalità ospitaliere per certi versi "concorrente" dei Templari.

CD III: n. 277, n. 281

CD IV: n. 3 . 
Gregorio IX. Nel $1224^{47}$ secondo Lago e Ferrari-Cupilli i Templari di Vrana possedevano il castello o rocca di Nona (Nin). Tale notizia, non riportata da alcun Autore contemporaneo, va presa con cautela in quanto non risulta specificata la fonte. Maggiori indicazioni fornisce Ferrari-Cupilli che fa riferimento a Simeone Gliubavaz, uno studioso zaratino del XVII secolo, e suppone ci possa essere stata confusione tra Templari e Ospitalieri. La precettoria di Vrana vide almeno due volte il passaggio di re Bela IV che soggiornò nel castello templare. ${ }^{48}$ La prima volta si rifugiò a seguito delle scorrerie mongole in Ungheria ${ }^{49}$ e la seconda (1245) per pacificare alcune città dalmatine..$^{50} \mathrm{Nel} 1224^{51}$ è ricordato fra' Averardo precettore di Vrana (frater Auerardus preceptor Vrane) in una questione relativa all'eredità della sorella di nome Stana,${ }^{52}$ nel medesimo documento sono menzionati altri Templari come testi, probabilmente dimoranti presso la domus: Cessario fratre et sacerdote et fratre Dominico.

Un'altra precettoria templare è documenta nel $1284^{53}$ a Zablaće (villaggio non più esistente, distrutto nel XVII secolo dagli Ottomani), a poca distanza da Vrana: in quell'anno sono menzionati il precettore di questa domus (fratris Johannis de Foys in Zablata preceptoris) e quello di Vrana con il suo vice e altri due frati (fratris Johannis de Athys preceptoris palacii ${ }^{54}$ de Auramia, fratris Petri de Beizeyo vicepreceptoris in Auramia e fratris Oliverii, fratris Thome), i quali davano il proprio consenso (consilio et assensu dilectorum in Christo fratrum nostrum) al maestro di Ungheria fra' Guglielmo de Peymes per assegnare una terra non coltivata e abbandonata nel territorio di Zablaće (quandam particulam terre nostre incultam, desolatam et vacuam in territorio nostro de Zablata Pazkaligna vocatam, sicut continuatur cum... usque ad mare et usque ad predium de Zablata, cum ceertis ipsius terre terminis, pratis, vineis, pascuis, arboribus, terris cultis et incultis) per l'utilità della domus templare, doveva trattarsi di una proprietà non utilizzata, al nobile di Zara Luca de Dessa, per i servigi resi all'Ordine templare; costui, e dopo di lui i suoi eredi maschi, per i primi due anni non dovevano nulla, in seguito erano tenuti a pagare un censo annuo di venti libbre ogni 15 agosto presso la precettoria di Vrana; i Templari si riservavano alcuni diritti relativi all'amministrazione della giustizia

\footnotetext{
47 LAGO 1869: 193 e FERRARI-CUPILLI 1889: 186-187. La notizia è riportata anche in Bianchi 1880: 270 ove si parla di una chiesa di San Gregorio con annesso monastero.

48 DE BENVENUTI 1940: 51-52.

49 Lago riporta che nel 1241 si rifugiò nel castello di Clissa cfr. LAGO 1869: 197.

50 LAGO 1869: 200.

51 CD III: n. 210.

52 Fra'Averardo si presentava cum quadam carta sigillata suo sigillo sostenendo che sua sorella Stana, vedova di Damiano Organe, aveva lasciato i propri beni a lui, mentre i nipoti della donna contestavano.

53 CD VI: n. 426.
} 
per i reati di omicidio, incendio e danni ai beni e alle persone. ${ }^{55}$ L'insediamento templare a Zablaće,${ }^{56}$ sorto probabilmente in un primo tempo come dipendenza di Vrana e poi divenuto autonomo nel corso del XIII secolo, potrebbe identificarsi con la chiesa di Santa Maria, della quale restano attualmente dei ruderi presso il sito archeologico di Crkvina (Pakoštane) sul versante occidentale del lago di Vrana. Sebbene tale chiesa è documentata a partire dal XV secolo, ${ }^{57}$ Kukuljevic $^{58}$ afferma dell' esistenza di un monastero templare a Zablaće. La struttura della chiesa, in stile romanico, è abbastanza complessa e presenta molte tombe di epoca diversa; in una di tali tombe è stato ritrovato un affresco con delle croci rosse su sfondo bianco che sembrano rimandare ad una presenza templare. ${ }^{59}$

Dal documento del 1284 apprendiamo quindi come nella precettoria di Vrana la comunità templare era formata da quattro frati, nel 1224 dovevano essere in tre, mentre quella di Zablaće era costituita dal solo precettore ed era quindi di più modeste dimensioni. In generale il personale delle domus occidentali era alquanto esiguo, di solito si aggirava intorno a 4-5 componenti per le fondazioni più grandi: il precettore, in genere un cavaliere, che era il responsabile della casa e il superiore della comunità, un cappellano che officiava le funzioni religiose, nelle case più piccole poteva anche non essere presente e in tale caso i Templari si avvalevano del clero locale, e poi vi erano altri fratelli, sovente sergenti, i cavalieri erano più utili in Terrasanta per combattere i Musulmani, impegnati in attività lavorative di tipo artigianale o agricolo. ${ }^{60} \mathrm{Negli}$ insediamenti di piccole dimensioni spesso era presente il solo precettore. ${ }^{61}$ Volendo effettuare un confronto con il numero di componenti nelle domus dell'altra sponda adriatica abbiamo che la fondazione di San Leonardo di Barletta, la principale nel Mezzogiorno italiano, nel $1196^{62}$ contava 9 frati: il precettore, un sacerdote e ben 7 altri frati dei quali non è detto a quale classe appartenevano, se cavalieri oppure sergenti. Nel $1228^{63}$ presso la chiesa di San Giovanni del Tempio di Foggia si trovavano 3 frati: il precettore, un sacerdote e un altro frate. Dai processi inquisitori emerge che nel $1292^{64}$ la

\footnotetext{
$\overline{54}$ Tale termine si riferiva al monastero-fortezza dei Templari. Palatium indicava un edificio fortificato cfr. LICINIO 1994: 128.

55 FERRARI-CUPILLI 1889: 176.

56 DOBRONIĆ 1984a: 60-61.

57 GUSAR E VUJEVIĆ 2013: 291.

58 KUKULJEVIĆ SAKCINSKI 1886: 35.

59 GUSAR E VUJEVIĆ, 2013: 273, 292.

60 FOREY 1997: 890-891.

61 FOREY 1997: 890.

62 CDB VIII, n. 173.

63 CAPASSO 1869: 10, nota n. 3.

64 SCHOTTMÜLLER 1887: 125-127.
} 
composizione della comunità templare di Barletta era la seguente: precettore, cappellano, siniscalco (probabilmente con funzione di vicario del precettore), sergente e un altro frate per un totale di 5 unità. Il confronto con le consistenze del personale presente presso le domus della costa dalmata e quelle del versante pugliese mostra come effettivamente Vrana fu un centro di un certo rilievo, sebbene la sua dimensione era sicuramente più limitata della casa di Barletta.

L'importanza della domus di Vrana, oltre che dal soggiorno di sovrani ungarocroati, è sottolineata anche da altri eventi. Si svolgevano cerimonie d'ingresso nell'Ordine come l'ammissione del sergente fra' Francesco da Genova da parte di fra' Jacobus de Moreau ${ }^{65}$ stando al resoconto dell'inquisizione del medesimo frate avvenuta a Cipro nel 1310. ${ }^{66}$ Fra' Francesco dichiarò di essere stato ricevuto 23 anni prima, quindi intorno al 1287, in Aurena de Sclavonia alla presenza di frater Franciscus de Valegi ${ }^{67}$ et frater Johannes de Membiliart, ${ }^{68}$ milites, et dominus Thomas ${ }^{69}$ de Aurana cappellanus de dicto ordine. Costoro sembrerebbero essere i frati dimoranti presso la precettoria di Vrana. Gli effetti della sconfitta di Acri giunsero anche in Croazia e nell' agosto $1291^{70}$ papa Nicolò III ordinò all' arcivescovo di Zara (Zadar) di convocare un concilio provinciale per decidere l'opportunità di fondere l'Ordine templare e quello ospitaliero. ${ }^{71} \mathrm{Nel} 1292^{72}$ è menzionato un frater Gregorius de Wrana chiamato assieme ad altri precettori ${ }^{73}$ a prendere delle decisioni di natura economica relative a diverse proprietà fondiarie con il maestro di Ungheria Guglielmo de Novis $^{74}$ a Zagabria (Zagreb). Potrebbe trattarsi del titolare della domus di Vrana o di un frate nativo di quella città; tuttavia dal contesto sembra più probabile la seconda ipotesi. Quando si trattava di prendere delle decisioni importanti queste

65 Secondo Schottmüller si tratterebbe di Jacques de Molay, futuro maestro generale dell'Ordine; di diverso parere Gilmour-Bryson: GILMOUR-BRYSON 1998: 115, nota n. 230. Non abbiamo indicazioni su dove de Molay si trovasse nel periodo 1285 - 1291: nel 1285 era a Parigi e nel 1291 in Terrasanta. Cfr. DEMURGER 2004: 64. Teoricamente potrebbe essere stato presente alla ricezione di Vrana.

66 SCHOTTMÜLLER 1887: 190.

67 Tale frate è menzionato anche nel 1292 cfr. CD VII: n. 79: fratris Franconis de Valegio socii nostri.

68 Potrebbe essere fra' Johannes de Monte Beliardo, precettore di Barletta nel 1292, menzionato nel processo di Brindisi cfr. SCHOTTMÜLLER 1887: 125-127.

69 Si potrebbe trattare dello stesso frate menzionato nel 1284 .

70 LAGO 1869: 215.

71 Sui progetti di fusione tra i due Ordini cfr. DEMURGER 2009: 408-412.

72 CD VII: n. 79.

73 fratris Franconis de Valegio socii nostri, fratris Wiliami de Brabancia preceptoris domus nostre de sancto Martino, fratris Rogerii preceptoris nostri de Glogonicha, fratris Gregorii de Wrana, et fratris Samsonis.

74 Su tale frate cfr. RICCI 2016: 140-141. 
venivano prese sempre in maniera collegiale dal maestro provinciale e dai precettori dell'area geografica interessata, sovente attraverso la convocazione di un capitolo provinciale. Se ne ha riscontro anche in territorio pugliese: nel $1196^{75}$ in occasione di una permuta con il vescovo di Canne erano stati interpellati dal maestro di Apulia Guglelmo de Sancto Paulo i precettori delle domus di Barletta, Trani, Brindisi e Salpi; qualche anno più tardi $\left(1213^{76}\right)$ vi fu una controversia tra i Templari e i canonici di San Leonardo di Valle Volaria per il possesso di due chiese e anche in tale circostanza il maestro provinciale Pietro de Ays aveva coinvolto i precettori delle domus di Capitanata (Foggia, San Quirico, Bersentino e Lama) nella soluzione della controversia. Nel $1298^{77}$ soggiornò presso il castello di Vrana il bano di Croazia Paolo (Pavao) Šubić, elemento ulteriore dell'importanza di questo sito. Nel $1310^{78}$, durante il periodo delle inquisizioni, il bano Paolo risultava essere patronus, advocatus et defensor ecclesie sancti Georgii de Laurana e aveva ricevuto il mandato apostolico di custodire e amministrare i beni sequestrati ai Templari, come risulta da un documento con il quale due ambasciatori del comune di Zara si recavano a Venezia per accordarsi sulle modalità di custodia delle reliquie dei Templari di Vrana.

Dopo il 1312 i beni templari passarono ai Giovanniti e Vrana continuò ad essere il centro principale di quest'Ordine nella regione..$^{79}$ Della struttura della fortezza templare, ubicata su una piccola elevazione naturale, rimangono solo imponenti rovine: due ampie corti rettangolari divise da un muro centrale, circondate da mura e un fossato; all'interno si possono vedere i resti della chiesa di San Gregorio.

\section{Le domus di Senj e Gacka}

Prima del $1183^{80}$ i Templari ebbero la città di Segna (villa Signye, attuale Senj) con la chiesa di San Giorgio, ${ }^{81}$ confermata da re Andrea nel 1209, ${ }^{82}$ quando

75 CDB VIII, n. 173.

76 CAMOBRECO 1913: 100, n. 158.

77 MS III: 432-433, n. 93.

78 MS I: n. 389.

79 SIRE 2008; ZANINOVIĆ 1993; GRAČANIN 2011.

80 CD II: n. 188. In quell'anno ricevano la conferma della donazione, che era stata fatta da re Bela III d'Ungheria (1172 - 1196), da parte di Lucio III: Lucius episcopus seruus seruorum dei dilectis filiis magistro et fratribus militie templi salutem et apostolicam benedictionem. Justis petencium desideriis dignum est nos facilem prebere assensum et vota, que a rationis tramite non discordant, effectu prosequente complere. Eapropter dilecti in domino filii vestris iustis postulationibus grato concurrentes assensu vilam Signye a charissirno in Christo filio nostro Bela illustri Hungarie rege cum omnibus pertinenciis pia domui vestre liberalitate collata cum ecclesia sancti Georgii - et omnibus, que in eodem loco de donatione regia rationabiliter possidetis, vobis et successoribus vestris apostolica auctoritate confirmamus. Dobronić e Margetić sostengono che la donazione avvenne nel 1180: cfr. DOBRONIĆ 1984a: 29; DOBRONIĆ 2003: 191-200; MARGETIĆ 2007: 96. 
prendeva i Templari e i loro beni sotto la sua protezione e impediva ai feudatari locali (bani) di esigere tributi. Si trattava del porto più importante del regno ungaro-croato nell'Adriatico settentrionale, ben collegato via terra con Zagabria e con l'Ungheria e punto di riferimento e transito per mercanti di Venezia, Ragusa (Dubrovnik), Veglia (Krk) e Arba (Rab); era utilizzato anche per i collegamenti con la Puglia e Ancona. Segna a quei tempi vantava un'organizzazione comunale abbastanza forte ed era anche sede vescovile. Per i Templari Segna ${ }^{83}$ fu un punto strategico ed ebbe un'importanza notevole dal punto di vista economico attraverso il controllo dei proventi derivanti dal commercio. Tramite il suo porto era possibile esportare i prodotti agricoli ricavati nelle fattorie della Slavonia. ${ }^{84} \mathrm{Nel} 1205$ in un documento relativo ad un accordo commerciale tra gli abitanti di Segna e quelli di Arba è menzionato il primo precettore di Segna: ${ }^{85}$ Terrinus frater templariorum Segniensium dominator ${ }^{86}$ tale titolo indica come il centro fosse un vero possesso feudale dei Templari, confermato anche dalla circostanza che il precettore agiva in rappresentanza della città di Segna. Particolarmente favorevole ai Templari fu re Andrea II di Ungheria che nel $1209^{87}$ confermava tutti i beni che l'Ordine possedeva in Croazia e nel $1219^{88}$ donò loro la vasta proprietà di Gacka (Gacko polje) a non molta distanza da Senj, definita nel documento come castri de Sten, sull'altro versante dei monti Valebit in Slavonia. Tale donazione è da mettere in relazione con l'aiuto logistico e finanziario che i Templari avevano fornito al re d'Ungheria-Croazia in Terrasanta durante la crociata ${ }^{89}$ e per il sostegno dato alla regina Jolanda che aveva governato durante l'assenza del marito avvalendosi come luogotenente del maestro provinciale dei Templari fra' Ponzio de Cruce. $\mathrm{Nel} 1226^{90}$ in un documento di Onorio III $^{91}$, il quale confermava la donazione di

81 Cfr. DOBRONIĆ 1984a: 64-65.

82 CD III: $\mathrm{n}$. 74: Civitas vero Scev, quam eis illustris B(ela) rex pie recordacionis in puram contulit elemosinam cum omnibus appendiciis suis, silvis scilicet et pascuis ceterisque ad ius regale spectantibus, ipsis fratribus semper firma permaneat et iure perpetuo inconcussa cum ecclesia beati Georgii in eiusdem civitatis territorio sita.

83 Sulla presenza templare a Segna: DOBRONIĆ 2003; BARTULOVIĆ 2007: 276-282.

84 KOSI 2001: 136.

85 Dobronić sostiene che una precettoria a Segna si ebbe solo dopo l'incendio della città avvenuto nel 1239: DOBRONIĆ 1984a: 65. Secondo il nostro parere già il qui menzionato frater Terrinus è da ritenersi a tutti gli effetti precettore, così come il frater Petrus menzionato nel 1233.

86 CD Supplementa 1: n. 22; CD III: n. 44.

87 CD III: n. 74.

88 CD III: n. 150.

89 Sulle crociate e la cronaca di Tommaso Arcidiacono cfr. GRAČANIN E RAZUM 2012.

90 PRESSUTTI 1895: n. 5912 e n. 5913.

91 Cfr. CD III: n. 228. Da questo documento non si evince il nome del maestro, in quanto forse illeggibile o non indicato (vi sono alcuni puntini): magistro et fratribus militie Templi in regno Vngarie. 
re Andrea II della terra di Gacka avvenuta nel 1219, è ricordato frater Hermannus magistro militie Templi in regno Ungarie.

Nel $1233^{92}$ una controversia commerciale tra zaratini e veneziani venne risolta nella precettoria di Segna (actum Signie coram Templi ecclesia in presentia suprascripti preceptoris) alla presenza del precettore (fratris Petri Signie preceptoris). La questione menzionata in precedenza nel 1205 ebbe un seguito nel $1234:{ }^{93}$ in un documento di quell' anno è ricordato un frate templare presente presso la fondazione di Senj: frater Radoslaus domus Templi de Segna qui dicitur Pristic; sebbene non riportato esplicitamente come precettore, potrebbe anche esserlo stato. ${ }^{94}$

Nel $1240^{95}$ il maestro della provincia di Ungheria, a seguito di quanto deciso dal capitolo provinciale, concedeva al monastero cistercense di Topusko di realizzare a Segna un magazzino (fondicum) dove conservare e commerciare i propri prodotti, dovendo però sottostare al controllo e ad alcune restrizioni imposte dai Templari, ${ }^{96}$ in caso di mancato rispetto dei patti avrebbero perso il magazzino. Bartulović ${ }^{97}$ sostiene che i cavalieri temevano la concorrenza commerciale dei Cistercensi. I Templari riscuotevano abitualmente una tassa per l'accesso nel porto $^{98}$ (arboraticum) che si pagava in base al tonnellaggio delle imbarcazioni come è ricordato in un documento del $1257^{99}$ relativo ad una controversia con dei mercanti di Ragusa che avevano trasportato un carico di legname a Segna. In tale circostanza è menzionato fra' Guglielmo precettore della domus di Segna che aveva imposto il diritto di arboraticum ai mercanti ragusei e questi si erano rivolti al podestà di Segna, nonché rappresentante del re di Ungheria-Croazia, sostenendo di non dover pagare alcuna tassa, in quanto le città della Dalmazia erano esentate da tale esazione. Il precettore templare controbatteva che l'arboraticum era dovuto poiché i Ragusei lo avevano sempre pagato quando trasportavano delle merci nel porto di Segna e portava a suo favore la testimonianza di un tale Desiam filium olim Miriesce che aveva esatto il tributo per conto dei Templari. Il podestà e i giudici di Segna però davano ragione ai mercanti di Ragusa che non dovevano alcuna tassa ai Templari per l'accesso al porto, sostenendo che se in passato avevano pagato erano stati costretti con la forza dai Templari. Anche sul versante pugliese dell'Adriatico in talune circostanze i Templari posero in essere dei tentativi di esazione forzata di diritti non dovuti, come a Barletta nel

\footnotetext{
Cfr. CD III: Appendice, n. 6

Cfr. CD III: n. 365.

94 Di tale avviso è DOBRONIĆ 2003: 94.

95 CD IV: n. 101.

96 DOBRONIĆ 2003: 194.

97 BARTULOVIĆ 2007: 279.

98 DOBRONIĆ 2003: 196.

99 CD V: n. 586.
} 
$1294^{100}$ e nel $1296^{101}$ quando i cavalieri richiedevano agli abitanti del posto il pagamento di diritti di affidatura (jus affidaturae) per il pascolo degli animali nelle terre templari che invece non dovevano essere pagati; i Barlettani si rivolsero al sovrano angioino che impartiva disposizioni ai balivi in merito. Tali atteggiamenti, sia l'episodio di Segna che quello di Barletta, mostrano come i cavalieri a volte si dimostravano abbastanza prevaricatori nei confronti delle collettività locali. Nel $1245^{102}$ sono menzionati i precettori di Segna e Gacka, fra' Giovanni e fra' Bernardo (frater Johannes preceptor Segniesis, frater Bernardus preceptor de Gecka) per una questione relativa ad una terra detta di San Giorgio a Gacka; ${ }^{103}$ da tale fonte apprendiamo che l'insediamento di quest'ultima località fu una vera e propria precettoria. Nel $1255^{104}$ fu stipulata una lega tra il comune di Zara e quello di Arbe contra homines Segne et Templarios, molto probabilmente per gravami fiscali applicati dai cavalieri ai danni di quelle città. Nel $1256^{105}$ i Templari ebbero una controversia con alcuni nobili per il possesso di un'altra terra a Gacka denominata Synch: i primi sostenevano che i cavalieri se ne erano appropriati con violenza all'epoca del bano Nicola, mentre il maestro di Ungheria fra' Jordanus, nel documento definito fidelis noster, affermava che il loro era un possesso pacifico. Alcuni decenni dopo, negli anni sessanta del XIII secolo, purtroppo la città di Segna e la contea di Gacka (civitas Zennye et comitatus Gwthke) furono sottratte ai Templari, con il consenso del monarca ungherese per essere assegnate al duca di Krk, con grave danno vista l'importanza strategica ed economica di questi due centri. ${ }^{106}$ Nella vicenda fu anche coinvolto papa Gregorio X nel 1274, ma alla fine i Templari dovettero rinunciare alle due città per ricevere in cambio nel 12691.500 marchi e la contea di Dubica ${ }^{107}$ (Bosanska/Kozarska Dubica) sulla quale esercitarono dei diritti feudali ${ }^{108}$. Sembrerebbe che la sottrazione di Segna sia anche da attribuire ai pessimi rapporti tra i cittadini del centro e i Templari. Le

\footnotetext{
100 CDB X: n. 151.

101 BATTI E BARONE 1904: 6.

102 CD IV: n. 241.

103 Tra i firmatari del documento figurava, oltre ai due precettori, anche un altro templare: frater Petrus miles de Borgona.

104 FERRARI-CUPILLI 1889: 176.

105 CD Supplementa 1: n. 160.

106 DOBRONIĆ 2003: 197-198; KOSI 2001: 137-138.

107 CD V: n. 975; THEINER 1859: n. 536: comitatum de Dwbicha com omni districtu, iurisdictione, honore ac suis pertinentiis.

108 Il maestro provinciale Franco si recò ad Acri per spiegare al maestro generale e al Convento i vantaggi e gli svantaggi della permuta, nonché per sottolineare i gravi danni che i cavalieri avrebbero subito per la perdita di Segna; egli ricevette il mandato per portare a termine l'accordo che fu poi ratificato da sovrani ungaro-croati Bela IV (1269), Stefano V (1270) e Ladislao IV (1272).
} 
fondamenta della chiesa di San Giorgio, ubicata al di fuori dell'abitato di Segna, sono state rinvenute nei pressi della torre di Nehaj. ${ }^{109}$

\section{Altri insediamenti}

Nel $1172^{110}$ sono menzionati due frati templari a Tinj: fratres templi nomine: Sadiluc et capelanus et diaconus Stoianus, la cui presenza potrebbe lasciare supporre l'esistenza di un insediamento o di una precettoria. Piuttosto difficili risultarono i rapporti tra i Templari e il monastero benedettino dei Santi Cosma e Damiano di Pasmano (Pašman): nel $1194^{111}$ il magister Gualterius era impegnato in una controversia con tale monastero relativa ad un corso d'acqua nella valle di Tinj, ${ }^{112}$ mentre nel $1221^{113}$ il maestro di Ungheria fra' Tommaso (magister Thomas templarius), insieme a frater Petrus Guizardus, era impegnato in una lite con l'abate Roberto del medesimo monastero per una terra a Tinj. I cavalieri possedevano anche una chiesa intitolata a San Pietro con annesso un ospedale a Boisce (Bojišče), nella diocesi di Nona (Nin), attestati nel $1186^{114}$ in un documento di papa Urbano III indirizzato a Matheo rectori et fratribus cruciferariis hospitalis sancti Petri de Boisce. ${ }^{115}$ Non sappiamo se tale denominazione indicava $1^{\prime}$ Ordine templare oppure un altro Ordine con finalità ospitaliere, ${ }^{116}$ potrebbe essere anche quello dei Crociferi di Santo Stefano re, al quale, si è visto in precedenza, apparteneva l'arcivescovo di Spalato Guncellus nel $1220^{117}$. Alcuni decenni più tardi, nel 1217, ${ }^{118}$ la chiesa risultava appartenere sicuramente ai Templari e presso tale mansione (appresso la casa ${ }^{119}$ nostra in san Pietro de Boischie) si trovava il

\footnotetext{
109 DOBRONIĆ 2003: 199-200.

110 CD II: n. 127.

111 CD II: n. 253

112 Tale vertenza ebbe seguito negli anni seguenti, infatti nel 1200 Innocenzo III si rivolgeva al magistro et fratribus militie templi in Sclavonia che lo avevano supplicato per una controversia con il monastero benedettino dei Santi Cosma e Damiano di Pasmano (Pašman) iniziata nel 1194. Cfr. CD II: n. 320.

113 CD III: n. 176.

114 CD II: n. 195.

115 Cfr. DOBRONIĆ 1984a: 59.

116 HUNYADI 2008: 260; BORCHARDT 2013: 419-420. Tale Autore sostiene che nell'Europa orientale i Templari erano spesso indicati nei documenti come cruciferi. Cfr. CD IV: n. 376: terra Cruciferorum templi nel 1250 a Požega (Croazia); CD IV: n. 532 cruciferos domus milicie Templi et hospitalarios nel 1255; CD VIII: n. 269 Cruciferorum militie templi nel 1312.

117 KUKULJEVIĆ SAKCINSKI 1896: 41, n. 125.

118 CD III: n. 139.

119 Tale denominazione lascerebbe pensare ad una fondazione, manca però nei documenti la menzione di precettori.
} 
maestro provinciale di Ungheria e Sclavonia fra' Ponzio della Croce (fra Pontio della Croce humile maestro della militia del Tempio per Vngaria et Sclauonia et locotenente regio in Croatia e Dalmatia ${ }^{120}$ ) per la risoluzione di una controversia tra il conte Domaldo e i cittadini di Trau (Trogir) che erano stati molestati dal predetto conte; il re, lontano dall'Europa in quanto impegnato in Terrasanta, affidò la protezione dei traurini al maestro dei Templari e un'assemblea di nobili croati decretava che le molestie avrebbero dovuto cessare, altrimenti il conte Domaldo e suo figlio sarebbero stati puniti dal re. Come si vede anche questo episodio mostra la fiducia riposta nei confronti dei Templari e del loro maestro provinciale, scelto come arbitro; fra' Ponzio dichiarava di aver convocato le parti e scelto la casa templare come sede della risoluzione della vertenza. Il maestro provinciale templare fu luogotenente del re Andrea II in Croazia durante la partecipazione del sovrano alla Quinta crociata. ${ }^{121}$ La chiesa di San Pietro dopo la soppressione dei Templari (1312) divenne di proprietà dei Giovanniti. ${ }^{122} \mathrm{Nel} 1188-1187^{123}$ è documentata una controversia tra i Templari e i Cruciferi della chiesa di Santa Croce presso Zara (controversiam inter fratres ord. Cruciatorum et Templarios de ecclesia s. Crucis prope Iadaren) che veniva risolta con l'intervento di Clemente III il quale inviava alcuni ecclesiastici suoi delegati (l'arcidiacono e l'arcipresbitero di Zara, Pietro della pieve di Santo Stefano e Matteo suddiacono della chiesa di Sant'Anastasia). La lite veniva risolta a favore dei Cruciferi rappresentati da fra' Matteo (potrebbe essere il medesimo personaggio che nel 1186 era rettore della chiesa di San Pietro di Boisce) ottenendo la conferma del papa della sentenza dei suoi delegati per il possesso della chiesa di Santa Croce a Zara (Clemens III fratri Mathheo Crucifero et aliis fratribus ord. Cruciatorum confirmat ecc. s. Crucis prope Iadarem $\left.{ }^{124}\right) . \mathrm{Nel}$ $1191^{125}$ Celestino III confermava nuovamente a fra' Matteo la chiesa all'Ordine dei Cruciferi. Da tali documenti si apprende come i Templari avessero tentato di appropriarsi della chiesa di Santa Croce di Zara entrando in conflitto con l'Ordine dei Cruciferi ${ }^{126}$, un Ordine religioso con finalità ospitaliere e assistenziali, molto probabilmente in "concorrenza" con gli stessi Templari. Prima della partenza in Terrasanta $\left(1217^{127}\right)$, Andrea II aveva donato all'Ordine templare il castello di

\footnotetext{
120 Il documento è redatto in volgare italiano.

121 KOSI 2001: 137; MATIĆ 2009: 374-380. Questo Autore sostiene che i Templari finanziarono la crociata di Andrea II.

122 HUNYADI 2008: 260.

123 KEHR 1909: 132, n. 1.

124 KEHR 1909: 132, n. 2.

125 KEHR 1909: 132, n. 3.

126 PACINI 2002; potrebbe trattarsi anche dell'Ordine dei Crociferi di Santo Stefano re per il quale si rimanda a BOROVICZÉNY 1991.

127 Thomas Archidiaconus Spalatensis 2006: 160-162.
} 
Clissa (Klis) ubicato in posizione strategica nell'hinterland di Spalato (Split) che controllava l'accesso a tale città ${ }^{128}$. Purtroppo i cavalieri possedettero solo per breve tempo questo importante castrum, infatti furono cacciati dagli spalatini che non sopportavano la vicinanza, ${ }^{129} \mathrm{e}$ in cambio ottennero la città costiera (castrum situm supra mare) di Sebenico ${ }^{130}$ (Šibenik). L'anno esatto di tale permuta non è noto e la notizia dello scambio tra i due castra è riportata in una lettera di papa Alessandro IV del $1255^{131}$ e riferita al tempo del regno di Andrea II (1205-1235). Sappiamo che il conte Domaldo ${ }^{132}$ di Cetina, il più potente feudatario nella Croazia meridionale, fu signore di Sebenico dal 1216 al 1220 e di Clissa dal 1225 al $1227 .{ }^{133}$ È quindi probabile che la permuta tra i due castra dovette avvenire tra il 1220 e il 1225. Al contrario di Senj, molto probabilmente a Sebenico i Templari non esercitarono mai dei veri e propri poteri feudali; ${ }^{134}$ essi dovettero svolgere la funzione di collettori delle tasse sul commercio per conto della Corona ungarocroata. ${ }^{135}$ Nonostante l'intervento di Alessandro IV il quale, tramite l'arcivescovo di Zara, esortava i cittadini di Sebenico a riconoscere e accettare l'autorità dei Templari136, dopo il 1255 essi furono allontanati definitivamente dalla città a causa di una rivolta dei suoi abitanti che mal ne sopportavano la presenza; in questa circostanza gli abitanti di Sebenico causarono anche dei danni ai Templari distruggendo la fortezza della città e le armi ivi contenute, ${ }^{137}$ ove verosimilmente si trovavano i cavalieri, e il papa ordinava agli abitanti di Sebenico di risarcirli. La cittadina veniva assegnata ai feudatari croati Šubić di Bribir, ${ }^{138}$ la cui signoria fu accettata con l'auspicio di potersi più facilmente liberare dalla sudditanza ai Templari. I cittadini speravano, inoltre, che i nuovi signori li avrebbero sostenuti nella lotta per ottenere una diocesi autonoma, come effettivamente avvenne nel

$\overline{128}$ FERRARI-CUPILLI 1889: 188-189.

129 FERRARI-CUPILLI 1889: 188.

130 ZELIĆ 1999.

131 CD IV: n. 520: memoriae Andreas rex Hungarorum quoddam castrum situm supra mare, quod Sibenich vulgariter dicitur, ad eumdem regem pertinens, cum ipsis pro quodam alio castro eorum, quod Clis vulgariter appellatur, permutans, ipsum eis cum suis pertinentiis ex abundanti nihilominus perpetuo concessisset.

132 KARBIĆ 1999: 35-39.

133 DUPLANČIĆ 2008: 245.

134 ZELIĆ 1999: 34-35.

135 ZELIĆ 1999: 33-34.

136 FERRARI-CUPILLI 1889: 189-190.

137 CD IV: n. 520: Populus tamen et homines habitatores eiusdem castri contra dictum magistrum et fratres, spiritu rebellionis assumpto, castrum ipsum temere occupantes, munitionibus et fortalitiis ipsius destructis, nolunt prout tenentur, eisdem magistro et fratribus super his intendere, aut cis debita exhibere servitia et de aliis suis iuribus respondere in ipsorum magistri et fratrum praeiudicium et gravamen. 
1298. ${ }^{139}$ Ferrarri-Cupilli afferma che a Sebenico i Templari ebbero la chiesa di San Salvatore con annesso un ospizio. ${ }^{140}$ Tale chiesa doveva essere all'interno della fortezza templare ubicata al di fuori delle mura cittadine all'incrocio di due importanti vie di comunicazione dell'insediamento medievale di Sebenico. ${ }^{141}$ Nel novembre $1312^{142}$ a Zara, dopo la soppressione dell'Ordine, è menzionato un frate Gregorius ${ }^{143}$ olim Templarius, all'epoca deceduto, che aveva lasciato al monastero di San Grisogomo la somma di 50 libbre destinate al fratello Matteo, campaio (guardiano di terreni) del predetto monastero, che rilasciava quietanza dopo aver ricevuto la somma ereditata.

\section{La presenza templare in Istria}

La presenza templare in Istria è caratterizzata dalla mancanza di fonti documentali che consentano un'attribuzione certa di alcuni insediamenti all'Ordine fondato da Hugues de Payns. Diversi siti ubicati nella penisola istriana sono stati ritenuti templari in modo alquanto dubbio in base alle affermazioni di studiosi del XIX secolo che vanno sempre presi con dovuta cautela. L'unica proprietà attestata risulta essere quella di San Michele di Leme, ${ }^{144}$ in precedenza monastero camaldolese in rovina per la poco attenta amministrazione da parte dei monaci. A causa della condizione in cui versava la struttura monastica, nell'aprile 1305 Bonifacio, vescovo di Parenzo (Poreč), decise di concederla in perpetuo ai Templari nella persona di fra' Symone de Auximo (Osimo) precettore di Santa Maria del Tempio di Venezia. ${ }^{145}$ La donazione avveniva con la clausola che, quando il patriarca di Aquileia o il legato pontificio richiedevano delle collette, i Templari avrebbero dovuto pagare la parte loro spettante ai canonici di Parenzo. Fra' Simone prendeva possesso del monastero dalle mani dell'arciprete Giorgio alla presenza di alcuni testimoni e i domina Agnesia, conversa del monastero, la quale giurò obbedienza al precettore templare e si impegnava a custodire San Michele e le

\footnotetext{
138 Su tale famiglia cfr. KARBIĆ 1999 e KARBIĆ 2005.

139 Cfr. KARBIĆ 2001 e PETROVIĆ 2016: 22-25. Secondo questo Autore dietro la creazione della diocesi di Sebenico vi sarebbero le pressioni degli Angioini su papa Bonifacio VIII; tale concessione favoriva la famiglia Šubić, feudataria di Sebenico, che avrebbe contraccambiato con l'appoggio alla causa degli Angiò nei diritti alla corona di Ungheria-Croazia.

140 FERRARI-CUPILLI 1889: 190.

141 ZELIĆ 1999: 35 ss.

142 CD VIII, n. 266.

143 Potrebbe trattarsi del frate Gregorius de Wrana menzionato nel 1292.

144 PEZZELLA 2004: 82-83.

145 MITTARELLI E COSTADONI 1755: 387-389.

146 MITTARELLI E COSTADONI 1755: 389.
} 
sue proprietà. ${ }^{146}$ La concessione ai Templari era giustificata con l'accoglienza e il passaggio dei pellegrini ${ }^{147}$ (in quo peregrinos euntes et redeuntes de ultramarinis partibus valeant recepturi). Ma possono essere individuati anche altri diversi motivi: in primo luogo la considerazione che di essi avevano sia il vescovo di Parenzo che il patriarca di Aquileia, ${ }^{148}$ poi, come emerge dall'atto di donazione, risultava che: predicti fratres (i Templari, n. d. r.) nullum habent locum in partibus Ystrie, affermazione che lascerebbe supporre che prima del 1305 l'Ordine rossocrociato non possedeva beni in Istria. Accanto a tali motivazioni più immediate va anche considerata l'influenza della politica papale a favore degli Ordini religioso-militari dopo la perdita di Acri (1291) con l'attribuzione di abbazie benedettine in decadenza a Templari (San Pietro a Torremaggiore nel 1295) e Ospitalieri (Santa Trinità di Venosa e Sant'Angelo in Palazzo nel 1297, Santo Stefano di Monopoli nel 1317) nel Mezzogiorno italiano. Il possedimento istriano era probabilmente una dipendenza della precettoria di Venezia, elemento questo che confermerebbe l'appartenenza del territorio dell'Istria alla provincia templare di Lombardia, che l'amministrava tramite la conversa Agnese. Dopo il 1312 San Michele di Leme tornò ai Benedettini e non fu assegnata agli Ospitalieri come avvenne in genere per i beni templari.

\section{Relazioni con il versante Adriatico occidentale: la Puglia}

I rapporti economici e commerciali tra la Puglia e l'altra costa dell'Adriatico (Istria, Dalmazia, ma anche Albania e Grecia) furono una costante in epoca medievale, soprattutto nel corso del XIII secolo ${ }^{149}$, anche se non mancano attestazioni per il secolo precedente, quando, ad esempio, nel 1148 Molfetta stipulava un accordo commerciale con Ragusa (Dubrovnik). La Puglia per Venezia e per la costa dalmata costituiva il principale mercato di approvvigionamento di frumento. Mercanti veneziani e dalmati ${ }^{150}$ erano soliti frequentare i porti pugliesi per cari-

\footnotetext{
147 Sulle strutture assistenziali e ospitaliere in Istria cfr. MOGOROVIĆ CRLJENKO 2002.

148 CAPONE 1997: 141.

149 Per approfondimenti su tale argomento cfr. CARABELLESE 1911: 85-97, 166-170; FEKETE NAGY 1927; POPOVIĆ-RADENKOVIC 1958; TADIĆ 1960; KREKIC 1962; DI VITTORIO 1994.

150 Tra marzo 1303 e aprile 1304 nel porto di Barletta sono documentati i seguenti mercanti dalmati (Cfr. NICOLINI 1972: passim.): Andrea Boni de Iadara con la nave Sanctus Nicolaus, Stephanus Crepannimanus de Iadara con la sua terida, Luca de Presca de Iadara con la barca chiamata Sanctius Nicolaus, Pascale de Trugirio, Bulcinus de Metafora de Iadara, Stephanus Compagnus de Iadara con la sua terida, Matheus de Iadara, Petrus de Iadara, Marinus Sparanthii de Iadara, Martinus de Spalato, Vitus de Iadara, Iohannes de Lanardo de Iadara, Laurentius de Spalato, Bannus de Budesiliano de Iadara cum panzone suo, Iacobus de Dragurio, Germanus de Spalato, Pluyas de Dragurio, Calendus de Draguro, Miriaco de Draguro con la sua barca, Damianus de Iadara, Vannus de Pago de Sclavonia (Pag), Palma de Ragusio, Matheus de Bastisio de
} 
care di grano le proprie imbarcazioni; Carlo I d'Angiò aveva concesso libertà di esportazione, di frumento dai porti Puglia verso le città dalmate e in Albania. Il frumento, proveniente dalla Capitanata, era inviato prima a Barletta e Manfredonia e da qui era concentrato nel porto di Brindisi da dove salpava per la costa orientale. ${ }^{151}$ Le principali città dalmate interessate agli scambi commerciali con la Puglia erano Ragusa (Dubrovnik), Traù (Trogir), Zara (Zadar), Spalato (Split) e Sebenico (Šibenik). Le esportazioni verso il regno di Ungheria e Croazia si intensificarono allorquando la dinastia angioina iniziò ad imparentarsi con i sovrani della casa Árpád per poi salire al trono di quel regno. Altri prodotti esportati sulla costa croata dalla Puglia erano l'olio e i legumi ed anche il sale. Accanto ai mercanti veneziani ben presto iniziarono ad inserirsi quelli toscani nelle relazioni commerciali con la Dalmazia. La guerra per Ferrara, protrattasi sino al 1316, causò un certo attrito tra Venezia e la corona Angioina: tale circostanza permise il rafforzamento della posizione delle grandi compagnie commerciali fiorentine (Acciaiuoli, Bardi e Peruzzi) nel commercio del grano in Puglia.

Per quanto riguarda le relazioni di natura economica e commerciale riferibili agli insediamenti templari possiamo annoverarne diverse relative all'utilizzo di imbarcazioni. In alcuni casi i Templari pugliesi ebbero dei contatti con armatori dalmati per il noleggio di navi da utilizzare nel trasporto di derrate alimentari in esenzione di imposta verso la Terrasanta. Nel $1272^{152}$ a Barletta i cavalieri rossocrociati armarono le seguenti imbarcazioni: la panzonis sire Benvenuti et sire Martini de Dragundo ${ }^{153}$ vocatii "Sanctus Nicolaus" e la panzonis Andree de Iadara, ${ }^{154}$ vocati "Sanctus Cristofonus". Accanto a queste vi era anche la nave San Nicola di un tale Nicola Stramatia di Bari e il vassellus sire Mani et Omniboni vocatii "Sanctus Albanus". Tale circostanza fa capire come i Templari non solo utilizzavano le imbarcazioni di armatori locali, ma anche quelle dalmate che spesso erano attraccate nei porti pugliesi. Nel 1242 il capitano e poi doge veneziano Ranieri

Iadara, Andrea de Iadara, Iohannes de Spalato, Matheus filii Lucii de Dragurio, Balcinius de Iadara, Vitus de Arbis, Dominicus de Iadara, Bractus Sclavus de Corthula (Korčula), Iohannis de Chersia (Cres), Criscius de Iadara, Matthias de Spalato, Stephanus de Arbis, Ybanus de Iadara, Stephanus de Iadara, Marinus de Iadara, Damianus de Spalato, Damnianum sire Dessi de Iadara, Iunius Costa de Cataro (Kotor), Yapranis de Iadara, Brayca de Iadara, Raymundus de Lesina de Sclavonia (Hvar), Sarathas de Spalato de Sclavonia, Felicius de Grado de Ragusio, Damianus de Frisionia de Iadara, Russus de Arbis, Martinettus de Spalato, Daniele de Arbis, Petrus de Bracza (Brač). Le destinazioni principali delle spedizioni di frumento erano Zara, Spalato, Arbe, Segna, Sebenico, Fiume, Corzula, Brazza, Lesina, Cherso, Pola, Ragusa, Parenzo, Traù, Cattaro, Scardona (Skradin).

151 CARABELLESE 1911: 96.

152 RA IX: 293-294, n. 22.

153 Traù.

154 Zara. 
Zeno riferiva di aver visto costruire delle navi templari nel porto di Zara; ${ }^{155}$ le navi dell'Ordine dovevano collegare abbastanza di frequente le località dalmate e quelle pugliesi: nel settembre $1275^{156}$ Carlo I d'Angiò scriveva al baiulo di Barletta che nel caso in cui una nave templare fosse salpata per l'Ungheria con il magistro domus eiusdem ordinis, non sappiamo se si trattava del maestro provinciale di Apulia o di quello di Ungheria, l'avrebbe dovuta fare attendere o far preparare un'altra per trasportare due o tre nunzi regi a Zara o a Segna; nel $1270^{157}$ un'altra nave templare era impegnata nel trasporto dal porto di Zara in Puglia di Maria Árpád d'Ungheria, futura consorte di Carlo II d'Angiò ${ }^{158}$; l'imbarcazione era comandata da fra' Giacomo di Ancona, frate successivamente presente a Brindisi verso il $1286 .{ }^{159}$ Come si è scritto in precedenza le città dalmate si rifornivano di victualia dalla Puglia e in alcune circostanze l'approvvigionamento riguardò anche le domus templari. Nel $1278^{160}$ Carlo I d'Angiò scriveva al portolano di Puglia di accordare licenza a fra' Girardo dell'Ordine templare per spedire in Ungheria via mare 30 salme di legumi dai porti pugliesi senza pagare alla Corona i diritti di spedizione. Si trattava di fra' Gerardo de Sauzet che nel 1278-1279 ${ }^{161}$ era maestro della provincia di Ungheria e Sclavonia e in alcuni documenti è menzionato semplicemente come fra' Gerardo, ${ }^{162}$ ma sempre con l'indicazione del suo titolo di maestro provinciale. Si osserva tuttavia che frate Gerardo che si occupò di inviare i legumi dai porti pugliesi nel regno di Ungheria-Croazia è citato senza l'indicazione del suo ruolo di magister per Ungariam et Sclavoniam, come un semplice frate templare (religioso viro fr. Girardo Ord. Militiae Templi); la mancanza della qualifica non è un elemento determinante per escludere che si trattava del maestro di Ungheria. Nel medesimo anno (1278) è attestata anche l'esportazione di grano dalla Puglia destinato alla domus di Vrana. Il 3 settembre ${ }^{163}$ Carlo I d'Angiò scriveva al magistro portulano et procuratori Apulie et Aprucii Angelo Sannelle di autorizzare la spedizione di 100 salme di frumento, senza dover pagare le consuete tasse portuali, dal porto di Manfredonia o da quello di Trani a Zara destinato al sostentamento dei frati della domus di Vrana (pro usibus fratrum et personarum domus predicte). Tale richiesta era stata avanzata da frate Franco, precettore di Vrana (supplicacionem religiosi viri, fratri Franci preceptoris

\footnotetext{
155 BARBER 1994: 238.

156 CARABELLESE 1911: 162, nota $\mathrm{n} .1$.

157 Maria d'Ungheria sposò Carlo lo Zoppo nell'agosto 1270.

158 RA IV: 49, n. 302 (senza data).

159 MICHELET 1851: 146-148.

160 RA XIX: 36-37, n. 136; CARABELLESE 1911: 166, nota n. 1.

161 RICCI 2016: 134-137.

162 CD VI: nn. 207, 218, 224, 252, 259.

163 RA XLIV: 593, n. 198, 630, n. 308.
} 
domus Templi existentis in Avarna, in partibus Sclavonie, devoti nostri). Un'altra spedizione di cereali è attestata due anni dopo nel $1280^{164}$ quando il sovrano angioino autorizzava il templare frater Robertus, senza pagare i diritti portuali, ad esportare 200 salme di orzo dalla Puglia, sebbene nel documento non sia indicato il porto di partenza, ma è quasi certo che si trattava di una località pugliese, nei porti di Zara e Zablaće pro usu ipsius domus templi. Il frate Roberto menzionato in questo contesto è fra' Roberto de Rupe o de Gudde, vice maestro della provincia di Ungheria nel 1280 che si trovava nel regno di Sicilia, del quale tratteremo in seguito. Sembrerebbe che un'altra spedizione di orzo ebbe luogo nel 1295, ${ }^{165}$ tuttavia si nota subito che il contenuto del documento è assolutamente identico a quello del 1280: è da ritenere che sia stato considerato due volte distintamente dall'Editore ${ }^{166}$ originario con l'attribuzione di due anni diversi, tra l'altro aventi la medesima indizione VIII. L'anno esatto dovrebbe essere il 1280 piuttosto che il 1295 , in quanto nel 1280 è attestato fra' Roberto in un altro documento. ${ }^{167}$

\section{Relazioni con il versante Adriatico occidentale: Venezia}

I rapporti ${ }^{168}$ tra l'Ordine templare e la Serenissima furono quasi sempre molto buoni, tipico esempio di vicinanza e di amicizia in Oltremare è rappresentato dalla guerra di San Saba. ${ }^{169}$ Quando la marina templare non si era ancora sviluppata, l'Ordine si avvalse dei servizi di Venezia per i trasporti marittimi, inoltre entrambi avevano interessi convergenti in Terrasanta. Tuttavia in alcune circostanze questa "intesa cordiale" ebbe dei momenti di crisi e le due potenze politiche furono su fronti opposti. Un episodio ebbe luogo nel 1202-1203 in occasione della Quarta Crociata, ${ }^{170}$ quella che portò alla conquista di Costantinopoli e alla fondazione dell'Impero Latino d'Oriente. I Veneziani e i loro alleati, diretti a Costantinopoli, occuparono e saccheggiarono la città di Zara. ${ }^{171}$ L'arcivescovo di Spalato, Bernardo di Perugia, personaggio abbastanza influente presso la corte ungaro-croata, con il tesoro regio custodito presso il castello templare di Vrana pagò 10 galee di Gaeta, di passaggio lungo le coste dalmate, a favore dei Zaratini e contro i Veneziani, aiutando i profughi nell'assalto del forte San Michele ${ }^{172}$ che fu smantellato. Indiret-

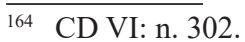

165 CD VIII: n. 187.

166 WENZEL 1874. Di seguito incontreremo altri casi di errata attribuzione dell'anno da parte di questa medesima fonte.

167 CD VI: n. 299.

168 PEZZELLA 2002: 53-57.

169 CLAVERIE 2009.

170 PHILLIPS 2009: 178-209.

171 PHILLIPS 2009: 191-195.

172 PEZZELLA 2002: 55.
} 
tamente, concedendo il tesoro che essi custodivano, i Templari si resero "complici" di questo atto contro i Veneziani. Tuttavia costoro dovettero soprassedere a tale avvenimento in quanto di certo i cavalieri rossocrociati non potevano sottrarsi all'obbligo di restituire il tesoro regio da essi custodito a Vrana. ${ }^{173}$

Nel dicembre 1239 la città di Segna, possesso dei Templari, fu incendiata e assediata ${ }^{174} \mathrm{e}$ alcuni mercanti delle città di Venezia, Arbe e Veglia subirono gravi danni. Nell'aprile $1248^{175}$ ebbe inizio nel palazzo ducale una transazione tra la Repubblica di Venezia, con il doge Jacopo Tiepolo, e i Templari, rappresentati da fra' Jacobo de Turrisellis, procuratore del maestro generale fra' Guillaume de Sonnac (1247-1250), da fratre Harmanno de Burgo, Preceptore in Campania et Marchia Tarvisana, et fratre Jordano, Preceptora Orane et Sennie, ${ }^{176}$ per il risarcimento da parte dell'Ordine templare per i notevoli danni subiti dai mercanti nell'incendio di Segna. Purtroppo dai documenti non si comprende bene il motivo della richiesta del risarcimento dai Templari, ritenuti in qualche modo coinvolti nella questione ${ }^{177}$, né tanto meno chi avesse attaccato e distrutto la città. ${ }^{178}$ Alcuni Autori ${ }^{179}$ hanno attribuito erroneamente l'incendio e la presa di Segna ai Templari guidati dal maestro di Ungheria fra' Rambaldo de Carono; esaminando il documento invece è riportato che l'assedio di Segna avvenne all'epoca in cui fra' Rambaldo ricopriva la carica di maestro della provincia di Ungheria ([...] civitate Sennie, quando capta et combusta fuit tempore fratris Rambaldi de Carono, Magistri Hungarie, currente anno Domini millesimo ducentesimo trigesimo nono, mense Decembri, indictione tercia decima [...]). Matić ${ }^{180}$ ritiene che l'incendio di Senj fu causato dai Templari per punire gli abitanti della città che si erano ribellati al governo dell'Ordine, rifiutando probabilmente di pagare i tributi. ${ }^{181}$ Nella transazione tra il doge e i Templari si stabiliva l'ammontare del risarcimento ai mercanti pari a 5.250 denari veneziani da pagarsi in tre rate annuali in occasione delle festa di

173 MATIĆ 2009: 377.

174 Molto probabilmente a seguito di tale episodio la città di Segna nel 1243 stipulò un accordo con la famiglia Babonić della Slavonia. Tale accordo fu ratificato anche dal Capitolo templare di Ungheria. Cfr. CD IV: n. 162: Vniuersitati uestre patefacimus, quod cum super inimiciciis inter nos videlicet, inter generacionem Babonik comitis et Stephani bani et populum Scenyensem exortis iuxta Templarios per preceptum domini regis ita.

175 MS I: n. 98, CD IV: n. 314

176 In questo momento storico le più importanti precettorie del litorale croato erano rette dal medesimo cavaliere.

177 Potrebbe essere stata riconosciuta una sorta di "responsabilità oggettiva" da parte dei Templari che governavano la città di Segna.

178 BELLOMO 2012: 822, nota n. 88; KOSI 2001: nota n. 112.

179 BRAMATO 1994: 124-125, n. 214; PEZZELLA 2002: 55.

180 MATIĆ 2009: 385.

181 MARGETIĆ 2007: 24. Tale Autore ritiene che i Templari erano malvoluti in Croazia. 
San Pietro nel mese di giugno ad iniziare dal 1249. I Templari furono esonerati dal pagamento di una parte dell'indennizzo, ma dovettero anche rinunciare alla richiesta del risarcimento dei danni subiti dal monastero di San Giorgio di Segna sofferto per mano degli abitanti Baška sull'isola di Veglia quando fuggirono lì nel 1242 a seguito dell'invasione dei Tartari. Il 3 maggio ${ }^{182}$ il doge Tiepolo con il Minor Consiglio per il Comune di Venezia e fra' Giacomo de Turrisellis, procuratore di fra Guglielmo de Sonnac dell'Ordine del Tempio, consegnavano ai Procuratori di San Marco due documenti relativi all'accordo preso dal Comune di Venezia per i danni portati ai mercanti veneziani. Il 10 febbraio $1250^{183}$ il doge Mario Morosini rilasciava quietanza a fra' Giordano, precettore di Senj e Vrana, di 1.750 denari veneziani quale prima parte delle tre dei 5.250 denari convenuti nella transazione tra la Repubblica di Venezia e il rappresentante del maestro generale templare. La questione si protrasse ancora per diversi anni giungendo sino al 5 agosto $1284^{184}$ quando intervenne ancora il Maggior Consiglio.

Vi sono diverse testimonianze sulla funzione di giudici in controversie esercitata dai Templari o l'utilizzo delle precettorie templari come luogo in cui pervenire ad accordi tra parti in lite. Il primo caso risale al $1233^{185}$ ed era relativo ad una controversia commerciale tra la comunità di Zara e il comite Giovanni Chigi, da una parte, e Jacobo Meronensi et Gabriele filio Telauiani de Ueneciis, dall'altra. La soluzione della controversia avvenne nella domus templare di Segna alla presenza del giudice Joseph filius Lorechene de Jadra e del precettore fratre Petro.

Decisamente più importante fu il ruolo svolto dalla domus di Santa Maria del Broglio di Venezia nella riappacificazione tra la Serenissima e Zara ${ }^{186}$ Gli abitanti di questa città si erano ribellati al dominio veneziano e nel $1247^{187}$ conclusero un accordo con il doge. La scelta della sede per la stipula dell'atto cadde sulla domus templare veneziana, molto probabilmente i cavalieri rossocrociati erano ritenuti dagli Zaratini degli interlocutori ben accetti, memori dell'episodio del 1202 menzionato in precedenza e del ruolo di non belligeranti da essi svolto durante l'assedio veneziano a Zara nel corso della Quarta Crociata. Inoltre i Templari avevano una presenza di un certo rilievo, come si è avuto modo di illustrare, sulla costa croata in località strategiche come Segna e Vrana. Gli Zaratini accettavano di sottomettersi al doge Giacomo Tiepolo, padre di Lorenzo Tiepolo, l'ammiraglio della flotta veneziana che si distinguerà nella guerra di San Saba in Terrasanta, alla presenza di fra' Alberto, maestro dei frati minori di Venezia e di frate Galzegna del medesimo

\footnotetext{
182 MS I: n. 99.

183 MAROZZO DELLA ROCCA E LOMBARDO 1940: 321-322.

184 MS I: n. 213; CESSI 1970: 77.

185 CD III: Appendice, n. 6.

186 PEZZELLA 2002: 59-60.

187 MS I: 68-74, n. 96.
} 
Ordine, di altri personaggi e soprattutto dei Templari: fratris Alberti presbiteri capellani milicie templi, fratris Leazarii eiusdem ordinis militie templi, Bonacursi clerici dicte sante Marie de Templo.

Un altro templare fu chiamato a svolgere il ruolo di giudice all'inizio del XIV secolo; si tratta di fra' Symone de Auximo, precettore della domus di Santa Maria del Broglio di Venezia. Tale frate nel $1303^{188}$ venne convocato a Capodistria (Koper), che all'epoca si chiamava Giustinopoli, come giudice in una lite tra il vescovo di Capodistria con il clero d'Isola (Izola), una località vicina. Davanti al precettore templare erano invitati a fornire testimonianza in favore del presule istriano Pietro Manolesso una serie di chierici locali: coram Dno. fratre Symone de Auximo priore domus Milicie templi Sce. Marie in capite brogli de venec. auditore seu examinatore testium producendor. ex parte capituli justinop. in questione quam habuit cum potestate et comune et clericis terre insule et cum Domino Gaspario et Domini almerici de dicta terra, et dicere quicquid sciret in questione vertente inter partes predictas. I tre episodi riportati dimostrano la grande considerazione che i Templari godevano nelle popolazioni nell'Alto Adriatico; erano ritenuti delle persone molto affidabili e super partes e per tanto chiamate a svolgere l'importante e delicata funzione di giudici e mediatori nella risoluzione di liti e controversie sia a carattere laico e sia a carattere ecclesiastico.

Vi è anche un'attestazione di attività di intermediazione finanziaria: negli anni precedenti i Templari avevano concesso molto probabilmente un prestito di denaro al comune di Zara, ottenendo come garanzia alcune reliquie e arredi sacri preziosi. ${ }^{189}$ Gli zaratini avevano provveduto a restituire la somma di denaro il 18 aprile $1308^{190}$ nella sagrestia del convento di San Grisogomo, tramite Guidone, abate di tale convento e procuratore del maestro templare fra' Damiano de Aftumello, (fratris Damiani de Aftumello magistri militie templi per Ungariam et Slauoniam) con la restituzione delle reliquie. Il 19 aprile ${ }^{191}$ Matteo Manolesso, comite Jadre, e Pietro Verniero e Marco Storiato, consiglieri di Zara scrivevano al doge di Venezia che, in seguito a suoi ordini, il comune zaratino aveva restituito un deposito di denaro al maestro della Provincia templare di Ungheria e Sclavonia.

\section{Relazioni riguardanti i cavalieri: mobilità e attività diplomatica}

La carriera dei frati era caratterizzata da mobilità sia a livello geografico che di incarichi gerarchici all'interno dell'Ordine. In genere dopo essere entrato nell'Or-

188 KANDLER 1862: 881, n. 495.

189 Le reliquie e gli arredi erano i seguenti: tre bracci di argento dorato di San Platone, San Gregorio e Santa Anastasia, tre croci argentate e dorate, una cassettina di avorio, due borse con reliquie, tre calici, un turibolo, due ampolle e una pisside d'argento. Cfr. BRUNELLI 1913: 436-437.

190 LJUBIĆ 1887: 109-110, n. 133.

191 PREDELLI 1876: 86, n. 366; MS I: n. 342. 
dine un frate prestava servizio in Terrasanta, dopo un certo tempo il Convento poteva inviarlo in Europa come semplice cavaliere oppure con la promozione a precettore a capo di una domus. La permanenza presso una medesima casa non era lunga e spesso si avevano cambiamenti delle fondazioni da guidare. In alcuni casi dei frati potevano essere richiamati in Oltremare sia per esigenze militari che di carattere amministrativo alfine di ricoprire ruoli più elevati nella gerarchia dell'Ordine, oppure potevano ricevere una promozione ulteriore, essendo scelti dal Convento per guidare una provincia con il titolo di maestro provinciale. Anche nella guida delle province i maestri potevano cambiare sede, anche più volte. Solo un ristrettissimo numero giungeva alle più alte cariche dei dignitari dell'Ordine, tra le quali quella di maestro generale.

I processi di mobilità territoriale dei cavalieri in alcuni casi riguardarono anche la guida della provincia di Ungheria. Un avvicendamento nella carica di maestro provinciale ebbe luogo alla fine degli anni novanta del XIII secolo. Si tratta di fra' Guglielmo di Noves (Novis), noto anche come Guglielmo Provintialis, ${ }^{192}$ nome che indicava l'origine geografica dalla Provenza, attestato come maestro di Ungheria nel $1292^{193}$ (frater Guyllermus de Nouis magister domorum milicie Templi per Hungariam et Sclauoniam) quando, con il consenso dei precettori delle altre domus di Croazia e Sclavonia, dava in pegno una terra (quod Gragena nuncupatur). Guglielmo dovrebbe essere entrato in carica in questa provincia qualche anno prima, in quanto nel $1290^{194}$ era titolare fra' Iacobo de Monte Regali. In precedenza era stato per diversi anni maestro della provincia di Lombardia, ${ }^{195}$ sicuramente attestato in un atto del 1285, ma menzionato anche in diverse testimonianze rese da frati durante le inquisizioni; tuttavia tali notizie, per quanto riguarda l'aspetto cronologico vanno prese come approssimative. Fra' Pietro da Bologna ${ }^{196}$ affermava di essere entrato nell'Ordine nel $1282^{197}$ a Bologna alla presenza di fratrem Guillelmum de Novis preceptorem tunc in Lombardia, mentre il serviente fra' Petrus Cadelli ${ }^{198}$ ricordava di essere stato ricevuto nel 1288 a Venezia da frater Guillelmus de Noves tunc preceptor in Lombardia. Molto probabilmente egli

192 MICHELET 1851: 239.

193 CD VII: n. 79

194 Budapest, National Archives of Hungary, Diplomatikai Levéltár (Diplomatics Archive), n. 40197. Una trascrizione del documento è pubblicata qui: WENZEL 1869: 114-115, n. 73; KUBINYI 1867: 16-17, n. 19. In entrambe i casi è riportato l'anno 1240 che è da ritenersi errato, in quanto all'epoca era maestro della provincia di Ungheria fra' Rambaldo de Caromb: CD III: n. 101. Per l'esatta datazione cfr. BELLOMO 2007: 101, nota n. 123.

195 BELLOMO 2007: 100-101, 365.

196 MICHELET 1851: 348-350.

197 Ma tale anno potrebbe essere errato in quanto in quel periodo era in carica il predecessore di fra' Guglielmo cfr. BELLOMO 2007: 98-99.

198 SCHOTTMÜLLER 1887: 209-210. 
lasciò la provincia di Lombardia per insediarsi in quella di Ungheria intorno al 1291, quando è menzionato, sebbene nelle testimonianze dei processi inquisitori, il successore nella provincia dell'Italia settentrionale fra' Artusio de Pocapalea. ${ }^{199}$

Un altro frate inviato dalla Lombardia in Ungheria, non con la carica di maestro provinciale, ma per motivi che non sono ben spiegati e desumibili dai documenti. Si tratta di fra' Guglielmo de Canelli ${ }^{200}$ che fu maestro provinciale in Sicilia dal 1284 al 1287. Non sappiamo per quali ragioni, molto probabilmente da collegare alle vicende della guerra del Vespro, fra' Guglielmo fu trasferito e messo a capo della Provincia templare di Lombardia verso il $1289-1290^{201}$ o più probabilmente all'inizio del 1291. Guglielmo apparteneva ad una nobile famiglia piemontese imparentata con Manfredi, il figlio di Federico II, e con gli Aragonesi e uno dei motivi del suo allontanamento dalla Sicilia potrebbe essere questo, anche perché all'interno dell' Ordine prevaleva la linea politica filo-angioina. Egli poteva essere "un personaggio scomodo nella lotta tra gli Aragonesi e Carlo II d'Angiò, anche in seno all'Ordine". ${ }^{202}$ Un certo interessamento per fra' Guglielmo fu mostrato dai sovrani d'Aragona. Nei primi mesi del 1290 Costanza d'Aragona, la figlia di Manfredi, rientrando in Sicilia al seguito del figlio Giacomo, scriveva al maestro generale Guglielmo de Beaujeu chiedendo il ritorno nell'isola del suo parente Guglielmo de Canelli con l'incarico di maestro provinciale. Il 23 maggio il maestro generale rispondeva alla regina madre da Acri mostrando il suo dispiacere nel non poterla accontentare poiché le consuetudini dell'Ordine consentivano lo spostamento dei dignitari, da un incarico all'altro, solo dopo che fossero trascorsi quattro anni, a meno che non si trattava di trasferimento per motivi disciplinari. ${ }^{203}$ Ritroviamo anche in questa vicenda l'influenza politica legata allo scontro tra Aragonesi e Angioini in Sicilia. Con la morte di Guglielmo de Beaujeu nel 1291 si sbloccò la carriera di fra' Guglielmo ed ottenne il nuovo incarico di maestro di Lombardia. I re di Aragona continuarono ad interessarsi del lontano parente templare e nel 1294 il sovrano scriveva una lettera di raccomandazione per fra' Guglielmo diretta al nuovo maestro generale Jacques de Molay per richiedere il suo trasferimento nella Penisola iberica. Tuttavia anche il filo-angioino de Molay ignorò le richieste del re d'Aragona, sebbene fossero trascorsi quattro anni dacché il templare era stato trasferito dalla Sicilia alla Lombardia. Nel 1296 fra' Guglielmo era ancora titolare della Provincia di Lombardia e risultava presente ad un Capitolo provinciale celebrato a Bologna. ${ }^{204}$ Tra la fine del XIII secolo

\footnotetext{
199 BELLOMO 2007: 101.

200 Su tale frate si veda BELLOMO 2007: 101-103; CAPONE E IMPERIO 1993: 140-146.

201 CAPONE E IMPERIO 1993: 140-146

202 CAPONE E IMPERIO 1993: 134.

203 CAPONE E IMPERIO 1993: 141.

204 CAPONE E IMPERIO 1993: 142.
} 
e l'inizio del XIV fu nuovamente trasferito, questa volta dalla Lombardia in Ungheria, non con funzioni di maestro provinciale in quanto intorno al 1300 in tale provincia la carica era ricoperta da un frate del quale è nota solo l'iniziale: magistro P. domus templi. ${ }^{205}$ Il trasferimento in Ungheria, forse una sorta di esilio per questo frate, è riportato in alcune deposizioni di Templari nei processi inquisitori nei territori papali. Fra' Gerardo da Piacenza ricordava la sequenza dei maestri della provincia di Lombardia: Guglielmo de Novis, Artusio de Pocapaglia e [...] Et post dictum fratrem Artusium fuit magnus preceptor frater Guillelmus de Canellis, qui fuit remotus de dicta preceptoria et missus in Ungariam, qui, ut audivit, rediens de Ungaria mortuus est reate. Et post dictum fratrem Guillelmo ipso adhuc vivente fuit magnus preceptor in illis partibus frater Huguico de Vercellis [...]. ${ }^{206}$ Secondo tale testimonianza fra' Guglielmo fu rimosso dalla propria carica dai suoi superiori e inviato in Ungheria. Un altro frate, Pietro Valentini, deponendo nelle inquisizioni sosteneva che [...] post amotionem dicti fratris Gulielmi missi in Ungariam, in dicta preceptoria, in Lombardia et aliis partibus supradictis fuit magnus preceptor frater Uguitio de Vercellis. ${ }^{207}$ Anche questa testimonianza lascia pensare ad una rimozione d'ufficio dalla provincia di Lombardia. Resta da capire qualche ruolo ebbe in Ungheria: funzioni ispettive? funzione di ambasciatore dell'Ordine? Non è per nulla chiaro. L'allontanamento forzato, deciso dai vertici dell'Ordine, ha decisamente il sapore di una vera e propria "punizione" del frate e la scelta dell'Ungheria, provincia remota e per certi versi "marginale", darebbe i connotati di un "esilio". Guglielmo avrebbe pagato ancora per la sua parentela con gli Aragonesi o per dissidi con i vertici dell'Ordine? Dietro l'allontanamento "potrebbe esserci stato un motivo dì ordine politico-disciplinare che trarrebbe origine dal vizio di forma nell'elezione a Gran Maestro di Jacques de Molay". ${ }^{208}$ Da quanto emerge da una deposizione del processo di Parigi sembrerebbe che al momento di eleggere il nuovo maestro generale dell'Ordine vi era un gruppo numeroso di cavalieri che avrebbe preferito Hugues de Pairaud a Jacques de Molay. Quanto questo frate si autoimpose le insegne di maestro, diversi fratelli si opposero e sorse una fronda interna, tanto che nel 1296 Bonifacio VIII dovette intervenire per richiamare all'obbedienza i frati ribelli ${ }^{209}$. Potrebbe essere che fra' Guglielmo de Canelli era tra gli oppositori al nuovo maestro, il quale avrebbe tentato di destituirlo, ma, forse per intervento del Capitolo, avrebbe poi optato per la soluzione di nominare fra' Uguccione

\footnotetext{
205 CD VII: n. 372. Il documento viene datato dall'Editore al 1300 circa.

206 GILMOUR-BRYSON 1982: 189.

207 GILMOUR-BRYSON 1982: 201.

208 CAPONE E IMPERIO 1993: 144-145.

209 CAPONE E IMPERIO 1993: 145.
} 
luogotenente in Lombardia ed inviare fra' Guglielmo in Ungheria ${ }^{210}$. Il frate sarebbe rientrato in Italia nel 1301, forse a seguito della notizia che Bonifacio VIII aveva convocato in Italia Carlo di Valois, fratello di Filippo il Bello, con un esercito, nel tentativo di pacificare gli stati pontifici e cacciare gli Aragonesi dalla Sicilia. Secondo alcuni testimoni del processo viterbese fra' Guglielmo da Canelli morì a Rieti. Non è dato sapere se il suo decesso avvenne prima di incontrare il papa oppure se fu al suo rientro da Roma.

La mobilità dei cavalieri non riguardò solo i maestri provinciali, ma anche semplici frati come caso di fra' Giovanni da Monte Beliardo. Costui intorno al 1287 era in servizio presso la domus di Vrana e partecipò alla cerimonia di ingresso nell'Ordine del sergente fra' Francesco da Genova, stando al resoconto dell'inquisizione del medesimo avvenuta a Cipro nel $1310 .{ }^{211}$ In tale circostanza è menzionato come frater Johannes de Membiliart. ${ }^{212}$ Intorno al 1292, frate Giovanni risultava essere precettore della domus di Barletta (frater Johannes de Monte Beliardo, miles dicti Ordini, preceptor domus de Barolo), secondo quanto affermato dal sergente fra' Johannes de Neritone $e^{213}$ che in un altro passo dichiarava che fra' Giovanni non poterat bene ire, quod grossas habebat tibias. Ė probabile che tale frate dopo il 1287 ottenne la promozione a precettore e la destinazione presso l'importante casa di Barletta.

Sono documentati diversi spostamenti di cavalieri dal Mezzogiorno nel regno di Ungheria-Croazia e viceversa. In alcuni casi si trattava di Templari ai quali furono affidate importanti missioni diplomatiche, in altri si trattava di spostamenti legati ad altre funzioni. Nel $1270^{214}$ fra' Giacomo di Ancona comandava una nave templare che portava da Zara in Puglia Maria Árpád d'Ungheria, futura consorte di Carlo II d'Angiò. Tale frate, esperto marinaio e comandate di navi, verso il 1286 si trovava presso la casa di Brindisi in occasione di una cerimonia di ricezione di nuovi cavalieri; ${ }^{215}$ all'epoca delle inquisizioni risultava deceduto secondo quanto affermava il sergente Bernardus de Alsonio nella sua deposizione. Un'altra testimonianza di spostamenti da una costa all'altra dell'Adriatico si ha nel $1275^{216}$ quando una nave templare doveva salpare per la Croazia con il magistro domus eiusdem ordinis, molto probabilmente il maestro di Ungheria che faceva rientro

\footnotetext{
$\overline{210}$ CAPONE E IMPERIO 1993: 145. Tali Autori sostengono con funzione di ambasciatore dell'Ordine.

211 SCHOTTMÜLLER 1887: 190.

212 Questa sarebbe la forma del cognome in francese, latinizzato, come avveniva all'epoca, in Monte Beliardo.

213 SCHOTTMÜLLER 1887: 125-127.

214 RA IV: 49, n. 302 (senza data).

215 MICHELET 1851: 146-148.

216 CARABELLESE 1911: 162, nota n. 1.
} 
nella propria provincia. Un altro maestro provinciale d'Ungheria era presente a Barletta intorno al 1304 per la cerimonia di ammissione nell'Ordine del sergente fra' Guido di Accon, come dichiarato dallo stesso frate durante le inquisizioni di Cipro del 1310; egli era stato ricevuto da Theouron de Provençea, tunc preceptor totia abbatie ${ }^{217}$ Ungarie nella casa del Tempio di Barletta 6 anni prima ${ }^{218}$. Si ignorano i motivi della presenza di questo maestro nel Mezzogiorno italiano e della sua presidenza nella cerimonia di ricezione, quando a Barletta di solito tali cerimonie era presiedute dal maestro provinciale di Apulia. Una possibile spiegazione potrebbe essere che tale carica all'epoca era vacante temporaneamente, in quanto proprio in quel periodo si ebbe un avvicendamento tra fra' Goffredo de Petraviridi e fra' Simon de Quincy. ${ }^{219}$ Molto probabilmente fra' Guido da Accon seguì il maestro di Ungheria in questa provincia dato che egli, nella sua deposizione, affermava di essere stato preceptor a Pasegale ${ }^{220}$ in Ungaria. ${ }^{221}$

I rapporti tra il Mezzogiorno angioino e il regno di Ungheria-Croazia si intensificarono a partire dalla primavera del 1269 quando, per iniziativa di Carlo I d'Angiò, furono intavolate delle trattative tra gli Árpádok di Ungheria e gli Angioini del regno di Sicilia per un doppio matrimonio tra il principe ereditario angioino Carlo (poi re Carlo II lo Zoppo) e Maria d'Ungheria e quello tra l'erede al trono croato-ungherese Ladislao (poi re Ladislao IV) e la terzogenita di Carlo I, Isabella. Il sovrano angioino riteneva l'Ungheria un importante alleato per i suoi progetti di conquista dell'Impero bizantino. In dicembre le trattative erano concluse e il matrimonio tra Carlo e Maria, giunta a Napoli nella primavera 1270 a bordo di una nave templare, fu celebrato il 6 agosto 1270. Nel luglio 1290 Ladislao IV di Ungheria, fratello di Maria, morì; costei da settembre 1290, dietro forti pressioni del marito, iniziò ad avanzare pretese sul trono ungherese, sebbene nel gennaio 1292 ad Aix-en-Provence rinunciò a tutti i diritti di successione a favore del primogenito Carlo Martello, che dopo qualche mese divenne titolare della corona di Ungheria. Tuttavia egli non poté far valere i propri diritti poiché aveva pochi sostenitori, concentrati soprattutto nella zona litoranea croata. Infatti la potente nobiltà e il clero ungherese fecero incoronare Andrea III detto il Veneziano, appartenente ad un ramo secondario della dinastia degli Árpádok. Questi morì senza eredi nel $1301 \mathrm{e}$, dopo un interregno che vide la presenza di tre sovrani riconosciuti dalle diverse fazioni della nobiltà locale, nel 1308 divenne re

\footnotetext{
217 Piuttosto singolare risulta la descrizione della carica di questo cavaliere, è menzionato come preceptor invece di magister e la provincia è definita abbatie. Potrebbe essere indicativo forse della scarsa conoscenza dell'organizzazione e della gerarchia templare da parte di fra' Guido.

218 SCHOTTMÜLLER 1887: 188-189.

219 Cfr. RICCI 2017: 76-89.

220 Attuale Požega in Slavonia (Croazia).

221 SCHOTTMÜLLER 1887: 312.
} 
d'Ungheria Carlo Roberto (Caroberto) d'Angiò, figlio di Carlo Martello. Aveva così inizio la dinastia degli Angiò d'Ungheria. ${ }^{222}$ L'interesse degli Angioini verso il regno ungherese determinò un sostanziale incremento delle relazioni tra il Mezzogiorno italiano e l'Ungheria. All'interno di queste vicende che portarono gli Angiò di Napoli su trono ungaro-croato un ruolo importante ebbero i Templari che in diverse circostanze svolsero funzioni diplomatiche. L'Ordine del Tempio ebbe sempre degli ottimi rapporti con gli Angioini e costoro si avvalsero spesso dei servigi dei cavalieri rossocrociati in diverse funzioni, ${ }^{223}$ tra cui quella di rappresentanti e di ambasciatori. Nel Medioevo i religiosi ricoprivano spesso tali ruoli sia per la loro preparazione culturale e amministrativa e sia per l'attitudine alla conciliazione. Per certi versi gli Ordini religioso-militari furono in questo degli anticipatori della missione spesso svolta in seguito dagli Ordini mendicanti per i loro frequenti contatti con il mondo laico, ${ }^{224}$ tenendo presente anche del carattere transnazionale e l'assenza di legami con entità statali. ${ }^{225}$

Molto probabilmente i Templari ricoprirono un qualche ruolo nel progetto del doppio matrimonio tra i membri della famiglia Árpád e quelli della casata angioina. Si è già scritto come Maria d'Ungheria giunse dalla Dalmazia nel regno di Sicilia a bordo di una nave templare; un ulteriore elemento è fornito dalla presenza in terra ungherese del maestro templare nel Mezzogiorno italiano fra' Stefano de Sissy, ${ }^{226}$ già maresciallo del Tempio, nella primavera del $1271 .{ }^{227}$ Non è noto il motivo del viaggio e della missione di tale frate, sappiamo solo che Carlo I d'Angiò ordinava ai suoi ufficiali di rispettare i beni dei Templari che erano sotto la sua protezione sino al rientro nel Regno del maestro provinciale de partibus Ungarie.

Un altro Templare che svolse probabilmente un ruolo delicato nelle questioni angioine in Ungheria fu un tale fra' Gerardo che abbiamo menzionato in precedenza nel $1278^{228}$ per l'invio di legumi dalla Puglia verso l'altra sponda dell'Adriatico. Vi sono buone ragioni per identificarlo con l'omonimo frate che nel medesimo periodo occupava la carica di maestro di Ungheria. Questi si recò nel regno di Sicilia a fine 1277 , molto probabilmente assieme ai nobili croati che sostenevano la dinastia angioina sul trono d'Ungheria-Croazia qualora si fosse aperta una successione, per conferire con Carlo I a Napoli. Nel gennaio $1278^{229}$ fra' Gerardo

\footnotetext{
222 Per maggiori approfondimenti sul governo angioino nel regno di Ungheria-Croazia cfr. DE REGIBUS 1934; HÒMAN 1938; KLANICZAY 2002; CSUKOVITS 2013.

223 Su tale argomento cfr. CARRAZ 2009; CARRAZ 2010; TOOMASPOEG 2011.

224 TOOMASPOEG 2012b: 765.

225 CARRAZ 2010: 21.

226 Su tale frate cfr. RICCI 2017: 47-48.

227 RA VII: 221, n. 1185 (18 maggio 1271).

228 RA XIX: 36-37, n. 136; CARABELLESE 1911: 166, nota n. 1.

229 RA XIX: 36, n. 135; CARABELLESE 1911: 166, nota n. 1.
} 
lasciava il Mezzogiorno italiano per fare il rientro nella propria provincia e il sovrano angioino lo autorizzava a partire dai porti pugliesi assieme a Volcectum (Vučeta ${ }^{230}$ ), cognato del bano Paolo (Pavao) Šubićc ${ }^{231}$ (c. 1245 - 1312), capo della fazione filo-angioina in Croazia, ${ }^{232}$ e otto familiares. Per benevolenza verso fra' Gerardo e verso il bano Paolo Šubić, nello stesso giorno, re Carlo autorizzava anche l'esportazione di legumi destinati ai Templari e di 200 salme di frumento e altrettante di orzo a favore del bano Paolo che tornava anch'egli in Croazia. ${ }^{233}$ Alcuni Autori ${ }^{234}$ riportano una seconda missione diplomatica svolta da fra' Gerardo nel regno di Napoli nel 1293, ma si tratta di un errore di datazione degli atti della cancelleria angioina compiuto da Wenzel, ${ }^{235}$ che ne fu il primo editore, dal quale ha attinto Kosi. In effetti sia nel 1278 che nel 1293 si ha la VI indizione; la datazione corretta di questi documenti è il 1278 come riportato sia da Carabelle$\mathrm{se}^{236}$ e sia Filangieri nella ricostruzione dei registri della cancelleria angioina. ${ }^{237}$ Il presunto secondo viaggio di fra' Gerardo del 1293, quando tra l'altro egli non era più titolare della provincia di Ungheria, è da ritenersi inesistente e non va collegato alle pretese di Carlo Martello che nel 1292 aveva assunto il titolo di re nominale di Ungheria-Croazia.

Il ricorso degli Angioini ai Templari per svolgere compiti diplomatici continuò ancora negli anni seguenti. Si avvalsero anche del successore di fra' Gerardo nella provincia di Ungheria ovvero di fra' Roberto de Rupe o de Gudde ${ }^{238}$ com'è menzionato nei documenti. Costui si recò nel regno di Sicilia nell'agosto 1280, molto probabilmente convocato dal sovrano angioino. Fra' Roberto doveva tenere i contatti tra gli Angioini e la nobiltà ungherese ${ }^{239}$ in vista di una possibile succes-

$\overline{230}$ Su questo personaggio cfr. KARBIĆ 2010: 140. L'Autore lo definisce come uno degli uomini più importanti dell'entourage del bano Paolo.

231 Su questo personaggio cfr. KARBIĆ 2005: 11-19.

232 Sul ruolo diplomatico svolto dalla famiglia Šubić nell'ascesa al trono di Ungheria-Croazia della dinastia angioina cfr. KARBIĆ 2010: 126-130.

233 RA XIX: 36, n. 134; CARABELLESE 1911: 166, nota n. 1.

234 KOSI 2001: 161, nota n. 131; CARRAZ 2009: 567-568, nota n. 101; KARBIĆ 2010: 127.

235 WENZEL 1874: 100-102.

236 CARABELLESE 1911: 166, nota $\mathrm{n} .1$.

237 In origine questi documenti si trovavano nel registro n. 28 di Carlo I e, come si può vedere dall'inventario di fine Ottocento di tali registri, la datazione è 1277 - 1278: cfr. Inventario cronologico-sistematico dei registri angioini conservati nell'Archivio di Stato di Napoli, Napoli 1894: 40-41.

238 Su tale frate cfr. RICCI 2016:137-138.

239 La notizia della presenza di fra' Robert de Gudde alla corte angioina è riportata in CARRAZ 2009: 568 che riprende a sua volta GUZZO 2003: 86. Tuttavia anche in questo caso viene commesso un errore di datazione, facendo risalire l'evento al 1295, mentre da altre fonti sappiamo che fra' Roberto de Gudde fu nel regno di Sicilia nel 1280. 
sione. Sulla via del ritorno in patria, egli passò da Barletta e quasi sicuramente dovette soggiornare presso la domus templare di San Leonardo. Durante la sua breve permanenza in questa località il 15 agosto $1280^{240}$ concedeva un prestito (mutuo gratis et amore, per indicare l'assenza di pagamento di interessi) di 20 marchi d'argento al templare fra' Alberto di Marsiglia. Tale somma di denaro serviva pro quibusdam rebus, quibus indigemus de ultra mare. Purtroppo nel documento non è leggibile una parte nella quale, probabilmente, si fornivano delle indicazioni sulla qualifica di fra' Alberto. Allo stato attuale non si hanno altre notizie su tale frate da altre fonti; è da escludere che fosse un frate della domus di Barletta, molto probabilmente era un cavaliere di passaggio in quella città, forse in servizio presso la provincia di Ungheria, visto che da questa aveva ricevuto il mutuo. Nel documento fra' Roberto è menzionato come fra' Roberto de Rupe vice preceptoris domorum milicie templi per Ungariam et Sclavoniam. Dopo qualche mese, ad ottobre, frate Alberto dava in prestito 70 bisanti d'oro ad un mercante di Zara il quale doveva restituire la somma di denaro entro Pasqua dell'anno successivo ${ }^{241}$. A fine agosto 1280 fra' Roberto de Gudde lasciò il regno di Sicilia: il 28 di quel mese Carlo I d'Angiò scriveva al Portolano di Puglia e Abruzzo di lasciar partire Fratrem Robbertum de Gudde Preceptorem Militie Domus Templi in Ungaria ad partes ipsa redeuntem cum equitatura et quatuordecim familiaribus suis, ${ }^{242}$ mentre il 31 autorizzava lo stesso frate ad esportare dalla Puglia 200 salme di orzo verso i porti di Zara e Zablaće per necessità delle domus templari del litorale croato ${ }^{243}$. È un chiaro atteggiamento di favore da parte degli Angioini nei confronti dei Templari, molto probabilmente da mettere in relazione con il ruolo diplomatico svolto dal maestro di Ungheria. Bisogna sottolineare come anche in questo caso vi è stata un'errata datazione dei documenti. ${ }^{244}$

Nel gennaio 1292 Carlo II d'Angiò riusciva a fare riconoscere i diritti del suo primogenito Carlo Martello sul trono ungaro-croato; tuttavia costui non fu accettato da buona parte della nobiltà locale. Iniziava una fase molto delicata per gli Angioini in Ungheria e in questo frangente essi decisero nuovamente di avvalersi dei servigi dei Templari nella veste di ambasciatori e rappresentanti.

\footnotetext{
$\overline{240}$ CD VI: n. 299.

${ }^{241}$ CD VI: n. 299.

242 WENZEL 1874: 66, n. 80. Pubblicato anche in RA XXIII: 56-57, n. 278.

243 WENZEL 1874: 67, n. 81. Lo stesso documento è riportato in CD VI: n. 302: Idem frater Robertus habet licentiam extrahendi per mare sine iure exiture salmas ordei ducentas farendas apud Jadaram et Zablacam pro usu ipsius domus templi. Datum aput Lacum Pensilemn ultimo augusti, VIII indictionis.

244 Gli stessi documenti menzionati in precedenza relativi alla presenza nel regno di Sicilia di fra' Robert de Gudde sono pubblicati una seconda volta da Wenzel sotto l'anno $1295 \mathrm{cfr}$. WENZEL 1874: 157, nn. 152-153. Sia il 1280 che il 1295 hanno la medesima indizione (VIII).
} 
Fu la volta di fra' Ugo di Monterotondo ${ }^{245}$ magister Sacre Domus Militie Templi in Regno e uomo di fiducia e consigliere (consiliarius et familiaris) del sovrano angioino. Carlo Martello nella primavera del $1292^{246}$ inviò 4 propri ambasciatori in Ungheria per ricevere l'omaggio della nobiltà e del clero. Tra gli emissari angioini ${ }^{247}$ troviamo fra' Ugo di Monterotondo definito viros religiosum, nobiles et discretos fratrem Hugonem de Monte Rotundo Ordinis Sacre Domus Milicie Templi; ${ }^{248}$ il sovrano raccomandava i propri ambasciatori ai nobili ungheresi ${ }^{249} \mathrm{e}$ pagava 26 once, ricevute in prestito da Iacopo Cantelmo, capitano di Napoli, per il viaggio degli ambasciatori in Ungheria. ${ }^{250}$ Hugo de Monte Rotundo nel corso della sua missione ${ }^{251}$ incontrò Paolo Šubić e i suoi fratelli Mladen e Giorgio ( $J u$ raj) ai quali consegnava una missiva di Carlo Martello che prometteva ai nobili croati lauta ricompensa se continuavano a sostenere il partito filo-angioino e a contrastare Andrea III il Veneziano, nel documento definito invasore del regno di Ungheria-Croazia. Per le spese della missione in Ungheria (pro expensis nunciorum ipsius missorum in Ungariam) il pretendente al trono otteneva un prestito di 30 once da un mercante fiorentino di nome Raynaldus Moccia e un altro prestito di 25 once dal vescovo di Capaccio. ${ }^{252} \mathrm{Nel}$ mese di luglio frate Hugo riceva una procura dal re per la sua missione ${ }^{253}$. Nel mese di agosto Carlo Martello scriveva al suo vicario in Ungheria Petro Rolandi di provvedere al trasferimento di fra' Hugo, ${ }^{254}$ della sua familia e dei suoi cavalli con spesa a carico della corona. ${ }^{255}$ Tra la fine del $1292^{256}$ e l'inizio dell'anno seguente Carlo Martello ordinava al proprio vicario in Ungheria di pagare ad Andrea bano di Zara 30 once per il nolo della terrida che aveva trasportato fra' $\mathrm{Hugo}^{257}$ e gli altri ambasciatori dal porto di Manfredonia sulle coste della Sclavonia. Il 2 febbraio del $1293^{258}$ il re effettuava

\footnotetext{
245 Su tale frate cfr. RICCI 2017: 68-71.

246 WENZEL 1874: 88-89, n. 105 (18 aprile); RA XXXVI: 48, n. 184 (18 aprile).

247 Gli altri ambasciatori erano Giovanni, vescovo di Ravello, Uguccione di Napoli, iuris civilis professoris, e il valletto Guarino de Boys .

248 WENZEL 1874: 87, n. 103 (5 aprile).

249 WENZEL 1874: 89-90, n. 106 (20 aprile).

250 RA XXXVII: 30, n. 111 (20 aprile).

${ }^{251}$ CD VII, n. 57 e n. 101. Il templare è definito: provido et religioso fratri Hugoni de Monte Rotundo, speciali nuncio et familiari nostro.

252 WENZEL 1874: 90, n. 107 (20 aprile).

253 RA XL: 87, n. 7 (17 luglio).

254 Nel documento è definito consiliarius et familiaris noster.

255 WENZEL 1874: 96, n. 118 (28 agosto).

256 CARABELLESE 1911: 165, nota $n .1$.

257 Definito nel documento discretus vir.

258 CARABELLESE 1911: 165, nota $\mathrm{n} .1$.
} 
un pagamento di 27 once a favore di Georgio Mathei de Iadara per il nolo di una sua terida che aveva trasportato fra' Hugo. Purtroppo dalla documentazione pervenuta, a parte i contatti con gli esponenti della famiglia Šubić, non sappiamo l'esito della missione in Ungheria del maestro della provincia templare di Apulia.

\section{Il ruolo dei Templari e dei Šubići nell'ascesa angioina al trono di Ungheria-Croazia: un'analisi comparativa}

Per la conquista del regno di Ungheria-Croazia un ruolo decisivo ebbero le missioni diplomatiche poste in essere dagli Angioini che videro come protagonisti i Templari ${ }^{259}$ e gli esponenti della famiglia Šubić, in primo luogo il bano Paolo. Si trattava in entrambi i casi di soggetti nei quali i re di Sicilia ponevano estrema fiducia. I Templari furono degli strenui sostenitori degli Angiò nel Mezzogiorno italiano, sia perché chiamati dal Papato e sia per la prevalenza nella seconda metà del XIII secolo dell'elemento transalpino alla guida dell'Ordine a livello provinciale (ricordiamo nella provincia di Apulia: ${ }^{260}$ Stefano de Sissy, Guglielmo de Beaujeu - questi era anche imparentato con gli Angioini -, Simone de la Tour, Pierre Le Griffier, Hugo de Monterotundo, Rainaldo de Varensis, Goffredo Peraverde Ultramontanus, Simon de Quincy e in quella di Ungheria: ${ }^{261}$ Gerardo de Sauzet, Roberto de Rupe, Guillermus de Suaseto, Jacobus de Monte Regali, Guglielmo de Novis, Theouron de Provençea) e a livello generale (ricordiamo tra i maestri generali: Guglielmo de Beaujeu, Thibaud Gaudin e Jacques de Molay, tutti di area francese). All'interno dell'Ordine, sebbene formalmente super partes, prevalse la linea filo-angioina, ${ }^{262}$ basta menzionare l'atteggiamento di Guglielmo de Beaujeu e di Jacques de Molay nei confronti di Guglielmo de Canelli imparentato con gli Aragonesi in conflitto con gli Angioini per il possesso della Sicilia (guerra del Vespro). In cambio della fedeltà templare i sovrani angioini concessero protezione, ${ }^{263}$ privilegi e soprattutto accordarono ai cavalieri la possibilità di esportare dai porti pugliesi frumento e altre derrate alimentari con destinazione Acri, Cipro e anche l'altra costa adriatica in regime di esenzione del dazio. ${ }^{264}$ In questo clima di reciproca fiducia e anche in ragione del prestigio, della popolarità e dell'importanza

\footnotetext{
$\overline{259}$ Sulle origini dei rapporti tra corte angioina e gli Ordini religioso-militari si rinvia a TOOMASPOEG 2012b: 763-767.

260 Sui maestri di questa provincia in epoca angioina cfr. RICCI 2017: 46-97.

261 Sui maestri di tale provincia cfr. RICCI 2016: 134-146.

262 Oltre all'elemento nazionale, occorre ricordare come gli Angioini furono chiamati dal papa nel regno di Sicilia per combattere gli Svevi ed essendo i Templari fedelissimi del pontefice non poterono che prestare fedeltà ai nuovi sovrani.

263 Si ricorda che restituirono ai Templari i beni che erano stati sequestrati dagli Svevi: TOOMASPOEG 2012b: 775.

264 TOOMASPOEG 2012b: 774-775.
} 
politico-militare dei Templari ${ }^{265}$ era quasi scontato che gli Angioni impiegassero tanto i maestri della provincia di Apulia che quelli della provincia di Ungheria con la funzione di emissari diplomatici nella questione della successione al trono ungaro-croato. L'utilizzo dei Templari della provincia di Ungheria può essere giustificato anche dall'influenza che essi potevano esercitare sulla nobiltà locale nell'opera di persuasione di adesione alla linea filo-angioina utilizzando il proprio ascendente. L'altro canale preferenziale fu quello della famiglia croata Šubić, una delle più influenti sull'altra sponda dell'Adriatico. I primi contatti tra Angioini e questa famiglia risalgono al 1274, quando i Šubići erano solo conti di Spalato e Sebenico, e sono da collegare alla funzione di contrasto ai pirati di Omiš che infestavano l'Adriatico, considerando la circostanza che i Šubići volevano assoggettare l'isola di Omiš al proprio dominio. ${ }^{266}$ Qualche anno prima, nel 1271, Carlo I d'Angiò aveva inviato come suo emissario il maestro della provincia di Apulia Stefano de Sissy in Ungheria, purtroppo non conosciamo per quale motivo, però sappiamo del costante interesse verso i Balcani e l'Oriente del sovrano angioino e il regno ungaro-croato poteva essere una conquista importante dopo l'Albania da realizzare non tanto con le armi, quanto piuttosto con la diplomazia, come poi effettivamente avvenne all'inizio del Trecento ${ }^{267}$ Contrariamente a quanto riporta Karbić ${ }^{268}$ i rapporti con gli esponenti della dinastia Šubić si intensificarono prima del 1290, anno della morte di Ladislao IV; nel $1275^{269}$ è attestata la notizia dell'invio di nunzi regi a Zara o a Segna, inoltre negli ultimi mesi del 1277 Paolo Šubić, dal 1275 bano di Crozia, ${ }^{270}$ si era recato nel regno di Sicilia assieme al cognato Vučeta e al maestro templare di Ungheria fra' Gerardo de Sauzet e nel gennaio $1278^{271}$ lasciavano il Mezzogiorno; per benevolenza Carlo I d'Angiò autorizzava una cospicua spedizione di frumento in direzione delle coste dalmate a beneficio del bano e dei Templari di quelle parti. ${ }^{272}$ L'esportazione di cereali dai porti pugliesi fu la ricompensa che gli Angioini accordarono sia ai Templari che ai Šubići per la loro fedeltà e il loro sostegno; occorre ricordare come la Puglia fu il principale mercato di approvvigionamento di derrate alimentari nel Basso Medioevo. Per i Templari la destinazione principale fu dapprima Acri, ultimo baluardo dei regni

\footnotetext{
265 TOOMASPOEG 2012b: 765-766.

266 KARBIĆ 2010: 126.

267 CARRAZ 2010: 28-29.

268 KARBIĆ 2010: 127.

269 CARABELLESE 1911: 162, nota $\mathrm{n} .1$.

270 Egli ricopriva tale carica dal 1273, ma nel 1274 era stato rimosso da Ladislao IV. Karbić suppone che la sua reintegrazione a bano di Croazia sia imputabile anche all'influenza di Carlo I d'Angiò sulla corona di Ungheria-Croazia in quanto suocero di Ladislao: cfr. KARBIĆ 2010: 126.

271 RA XIX: 36, n. 135; CARABELLESE 1911: 166, nota n. 1.

272 RA XIX: 36, n. 134; CARABELLESE 1911: 166, nota n. 1.
} 
latini in Terrasanta, e poi dopo il 1291, Cipro come ampiamente documentato dai registri della Cancelleria Angioina, ${ }^{273}$ mentre sono attestate solo alcune spedizioni verso il regno di Ungheria-Croazia; diverso è il discorso per i Šubići per i quali sono attestate moltissime spedizioni di frumento come riportato da Karbićc ${ }^{274}$ per il periodo da novembre 1291 a settembre 1303, anche se in realtà esse iniziarono già dal 1278 , come visto pocanzi, e durarono sino ad ottobre $1303 .{ }^{275} \mathrm{Il}$ movente di natura economica, ovvero il costante approvvigionamento di grano dei territori sotto il dominio dei Šubići, assieme alla possibilità di accreditarsi presso la corte ungaro-croata furono i principali fattori che determinarono l'alleanza tra $i$ nobili croati e gli Angioini; d'altro canto costoro avevano bisogno del bano Paolo Šubić e dei suoi fratelli per concretizzare le proprie mire espansionistiche verso l'Ungheria intessendo rapporti diplomatici e ottenendo consenso nell'altra sponda adriatica. ${ }^{276}$ Nell'estate 1280, ${ }^{277}$ il maestro di Ungheria fra' Roberto de Rupe (o de Gudde) era presente nel regno di Sicilia molto probabilmente per prendere contatti con la corona angioina, che lo ricompensò con la spedizione di grano in Croazia. ${ }^{278} \mathrm{Nel} 1290$ moriva Ladislao IV e tale evento apriva agli Angioini le porte del regno ungaro-croato: in tale frangente i rapporti tra i Šubić e Templari da un lato e Carlo II d'Angiò si rafforzarono, con la presenza di diversi emissari croati a Napoli tra il 1291 e il 1303 e talvolta anche degli stessi Paolo e Giorgio Šubić. ${ }^{279}$ Nel gennaio 1292 Carlo II d'Angiò riusciva a fare riconoscere i diritti del suo primogenito Carlo Martello sul trono di Ungheria-Croazia senza essere però accettato da buona parte della nobiltà locale; l'invio di fra' Hugo de Monterotundo prima in Croazia e poi in Ungheria nella primavera del medesimo anno è chiaramente da leggersi in ottica diplomatica e dell'allargamento del consenso attorno al pretendente Carlo Martello. Giunto sulle coste dalmate il templare ebbe un importante incontro con i fratelli Šubić, ${ }^{280}$ latore della promessa dell'Angioino di ampliamento del potere feudale e politico della famiglia nello scacchiere croato

\footnotetext{
273 Sulle spedizioni dai porti pugliesi cfr. RICCI 2014: 92-106.

274 KARBIĆ 2010: 126, nota n. 6.

275 Sono documentate altre spedizioni di frumento al bano Paolo Šubić dal porto di Barletta non considerate da Karbić: il 15 ottobre 1303 per Maiestatem Regiam concessis il comite Donaldus Scardonus nuncius domini Pauli Bani comitis Croatorum poteva esportare in esenzione di imposta un primo carico di 150 salme e un secondo di 1.000 salme da inviare ad terras et loca fidelium domini nostri regis cum galea Iacobis Patronis de Veneciis vocata Sanctus Nicolaus (NICOLINI 1972: 623). Altre 200 salme erano inviate il 21 ottobre (NICOLINI 1972: 624). Su Donaldus de Zadulinis conte di Scardona cfr. KARBIĆ 2010: 139.

276 KARBIĆ 2010: 126-127.

277 WENZEL 1874: 66, n. 80. Pubblicato anche in RA XXIII: 56-57, n. 278. 
qualora l'avessero sostenuto nella conquista del trono. In effetti Carlo Martello confermò a più riprese e garantì ai Šubići il possesso su buona parte della Croazia medievale, Paolo ottenne nel 1295 il titolo di bano di Croazia a vita. ${ }^{281}$ Non è da escludere, sebbene non documentato, un comportamento simile nei confronti dei Templari della provincia di Ungheria che avevano sempre goduto del favore della dinastia regnante in Ungheria-Croazia, così come non sappiamo se dietro la donazione nel $1295^{282}$ ai Templari della provincia di Apulia del monastero benedettino di San Pietro di Torremaggiore (con tutti i suoi possedimenti in Capitanata) da parte di Bonifacio VIII ci siano state pressioni angioine sulle decisioni del pontefice.

All'interno dei rapporti tra Angioini, Šubići e Templari non si può trascurare il ruolo del Papato, uno dei più importanti sostenitori dell'ascesa angioina in Ungheria-Croazia, che intrattenne rapporti positivi anche con la famiglia Šubić, ${ }^{283}$ molto probabilmente per garantire ulteriormente il loro supporto alla causa angioina. Il Papato, nella persona dell'energico Bonifacio VIII, voleva intervenire nell'organizzazione ecclesiastica della Croazia e in tal senso va vista la creazione della diocesi di Sebenico nel 1298, dietro la quale Petrović2 ${ }^{284}$ ritiene vi sarebbe la longa manus degli Angioini che avrebbero fatto pressione sul pontefice per avvantaggiare i Šubić, feudatari di Sebenico, ${ }^{285}$ in cambio del loro sostegno dei diritti della casa d'Angiò nel regno ungaro-croato. Inoltre Clemente V si servirà di Paolo Šubić per controllare le proprietà templari di Vrana dopo l'avvio del processo inquisitorio. ${ }^{286}$ Non è dato sapere se la presenza a Barletta del maestro di Ungheria fra' Theouron de Provençea ai primi del Trecento abbia avuto anche finalità di tipo diplomatico o meno, ovvero se il frate si recò anche presso la corte angioina di Napoli in qualità di emissario. Nel 1300 Caroberto, giovane figlio del defunto pretendente Carlo Martello, lasciò Napoli per recarsi in Dalmazia con l'aiuto dei Šubić; ${ }^{287}$ dopo la morte dell'ultimo sovrano Árpád e un periodo di turbolenza nel 1310 fu incoronato re di Ungheria-Croazia. Nei primi anni del XIV secolo le relazioni tra Angioini e Šubići si allentarono, in primo luogo per la morte dei protagonisti (Giorgio morì nel 1303, Carlo II d'Angiò nel 1308 e Paolo nel 1312) e poi perché il nuovo sovrano di Napoli Roberto il Saggio non aveva più interesse ad influire sul governo del nipote in Ungheria. ${ }^{288}$ Allo stesso modo

\footnotetext{
281 KARBIĆ 2010: 129.

282 TOOMASPOEG 2012a: 202.

283 KARBIĆ 2010: 130-132.

284 PETROVIĆ 2016: 22-25.

285 Karbić sostiene che i Šubići erano interessati a una migliore organizzazione ecclesiastica nei propri domini. Cfr. KARBIĆ 2010: 130, nota n. 45.

286 MS I: n. 389.

287 KARBIĆ 2010: 128.

288 KARBIĆ 2010: 129.
} 
cambiò l'atteggiamento angioino nei confronti dei Templari dopo l'avvio delle inquisizioni nel regno di Napoli (1308) provvedendo al sequestro dei loro beni e allineandosi con la politica del parente francese Filippo IV il Bello. ${ }^{289}$

\section{Conclusioni}

L'insediamento templare nell'attuale Dalmazia interessò principalmente la zona costiera, o a pochi chilometri dal mare, in modo da poter utilizzare le strutture portuali per i collegamenti con la Terrasanta, ${ }^{290} \mathrm{ma}$ anche con i porti italiani. Tali località costiere si trovavano inoltre lungo l'itinerario commerciale che portava da Venezia verso l'Oriente. Le navi templari dovevano collegare abbastanza di frequente le località dalmate e quelle pugliesi. La fondazione più importante fu quella di Vrana, centro nevralgico dell'Ordine nella provincia di Ungheria; per alcuni anni risulta documentata la composizione dei frati che dimoravano presso quella casa: nel 1224 se ne trovavano 3 (il precettore, il cappellano e un altro frate), mentre nel 1284 erano in 4: il precettore, il suo vice e 2 frati. Tali numeri sono indicativi di come si trattò di un insediamento di un certo rilievo, con valori in linea con il dato medio e abbastanza simili alla composizione delle precettorie del versante opposto dell'Adriatico.

Sui possedimenti del litorale croato molto influirono le decisioni della corona croato-ungherese sia attraverso le donazioni che con le spogliazioni come nel caso dell'importante porto di Senj, città infeudata ai Templari e fonte di notevoli entrate portuali. In molti casi si trattò di vere e proprie infeudazioni di città fortificate (castra). Bisogna sottolineare i rapporti difficili tra i Templari e le popolazioni che abitavano nei loro feudi: abbiamo testimonianza di almeno tre casi nei quali i cavalieri furono cacciati, costretti ad abbandonare o a dover permutare i propri beni feudali. Si tratta di Clissa, di Sebenico e di Senj. Purtroppo non sono ben note le motivazioni per le quali gli abitanti di questi tre centri si rivoltarono contro $\mathrm{i}$ Templari, ${ }^{291}$ se dietro vi erano delle vessazioni da parte dei cavalieri o altre cause. Margetić afferma che i Templari erano malvoluti in Croazia. ${ }^{292}$ Non mancarono occasioni di conflitti con altre istituzioni ecclesiastiche o civili, come si è riportato, altro elemento sintomatico di un rapporto non semplice con le collettività locali: nel $1256^{293}$ ebbero una lite con alcuni nobili per il possesso di una terra a Gacka,

289 DEMURGER 2009: 442.

290 MATIĆ 2009: 368 ss.

291 L'incendio di Segna viene interpretato da alcuni Autori come una ritorsione dei Templari ai danni degli abitanti che si erano ribellati e non volevano pagare i tributi dovuti ai cavalieri in quanto feudatari: MATIĆ 2009: 383-385.

292 MARGETIĆ 2007: 24.

293 CD Supplementa: n. 160. 
mentre nel $1257^{294}$ ebbero una diatriba con dei mercanti di Ragusa per il pagamento del diritto di arboraticum. Molteplici furono le controversie con il monastero di Pasmano per questioni inerenti le proprietà confinanti; in alcune circostanze ebbero luogo anche con degli episcopî, come nel 1169 - $1170^{295}$ con il vescovo di Scardona Lampriudius per il possesso del monastero di Vrana. Non mancò qualche contrasto anche con l'Ordine dei Cruciferi con il quale condivideva alcune finalità assistenziali e ospitaliere. La conflittualità con altre istituzioni religiose è una caratteristica che si riscontra anche sul versante opposto dell'Adriatico nelle domus di Capitanata ${ }^{296}$ dove sono documentati attriti tra gli insediamenti templari con i canonici di San Leonardo di Siponto (1213) per il possesso di alcune chiese, con l'abate del monastero di Santa Maria di Pulsano (1219), con i benedettini del monastero di San Pietro di Torre Maggiore (1225) e con i Cistercensi di Casanova (1226). Alla base della litigiosità vi era l'intraprendenza economica dell'Ordine templare e, in parte, anche il timore della concorrenza di questo nel ricevere le donazioni da parte dei benefattori.

Sono state analizzate le relazioni concernenti l'Ordine militare tra quattro aree geografiche: Puglia, Venezia, Istria e Dalmazia. Esse furono di natura economica e commerciale per la funzione da sempre svolta dalla Puglia di "granaio" dell'Adriatico e interessarono tanto i mercanti veneziani che le città portuali della Croazia. Si ebbero spedizioni di grano e legumi dalle domus templari pugliesi a quelle della provincia di Ungheria, molto probabilmente fu una manifestazione di benevolenza da parte degli Angioini di Napoli verso i Templari impegnati in un ruolo abbastanza delicato nelle fasi cruciali della successione nella monarchia ungaro-croata. Risulta abbastanza evidente la funzione diplomatica svolta dai Templari nella complessa vicenda dell'ascesa al trono degli Angioini in Ungheria; si è visto come attori di prim'ordine furono i maestri provinciali del regno di Sicilia, inviati in missione nelle terre ungheresi e per tenere i contatti la nobiltà del posto per sostenere i pretendenti angioini, e quelli di Ungheria talvolta presenti presso la corte di Napoli e in transito dai porti pugliesi per fare il rientro nella propria provincia. Sebbene non chiaramente documentato, i Templari ebbero un ruolo chiave nelle relazioni diplomatiche tra gli Angioini di Napoli e la nobiltà ungherese. Altro aspetto emerso è quello dei rapporti tra Venezia e l'Istria e il litorale croato, in particolare la città di Zara. In tale contesto si è osservato il ruolo super partes dei Templari, ritenuti interlocutori affidabili dagli zaratini tanto da scegliere la loro precettoria per stipulare la pace con Serenissima e sovente chiamati a svolgere il ruolo di giudici nelle controversie civili, come nel caso di Segna, o ecclesiastiche, come in quello di Capodistria.

\footnotetext{
294 CD V: n. 586.

295 CD II: n. 120.

296 TOOMASPOEG 2012a: 206.
} 


\section{Bibliografia}

Fonti

BATTI, Raffaele, Nicola BARONE. 1904. Repertorio delle Pergamene della Università o Comune di Barletta (1234-1638). Napoli.

CAMOBRECO, Ferdinando. 1913. Regesto di S. Leonardo di Siponto [Regesta Chartarum Italiae, 10]. Roma.

FEJÉR, György. 1832. Codex diplomaticus Hungariae ecclesiasticus ac civilis, t. VII, vol. II. Budae.

FILANGERI, Riccardo. 1963-2010. I Registri della Cancelleria Angioina ricostruiti da Riccardo Filangieri con la collaborazione degli archivisti napoletani. Napoli (abbreviato in RA).

FILANGIERI DI CANDIDA, Riccardo. 1927. Pergamene di Barletta del R. archivio di Napoli (1075-1309), Codice diplomatico barese, X. Bari (abbreviato CDB X).

KANDLER, Pietro.1862. Codice diplomatico istriano, III. Trieste.

KEHR, Paulus Fridolinus. 1909. Italia pontificia, IV. Berolini.

KUBINYI, Ferencz.1867. Codex diplomaticus Arpadianus. 1095-1301. Pest.

KUKULJEVIĆ SAKCINSKI, Ivan. 1896. Regesta documentorum regni Croatiae, Dalmatiae et Slavoniae, saeculi XIII. Zagabriae.

LJUBIĆ, Sime. 1868-1872. Monumenta spectantia historiam Slavorum Meridionalium, Listine o odnošajih izmedju južnog Slavenstva i Mletačke Republike. Zagreb (abbreviato in MS).

LJUBIĆ, Sime. 1887. Dva popisa listina (908-1782) glasovitoga manastira sv. Krševana u Zadru. s. 1.

MAROZZO DELLA ROCCA, Raimondo, Antonino LOMBARDO. 1940. Documenti del commercio veneziano nei secoli XI-XII, II. Roma.

MICHELET, Jules. 1851. Procès des Templiers, II. Paris.

MITTARELLI, Giovanni Battista, Anselmo COSTADONI. 1755. Annales Camaldulenses, $\mathrm{V}$. Venetiis.

NICOLINI, Nicola. 1972. Sul traffico navale barlettano dal marzo 1303 all'aprile 1304. In Michele Paone (a cura di), Studi di storia pugliese in onore di Giuseppe Chiarielli, II, 607-632. Galatina.

NITTI DI VITO, Francesco. 1914. Le pergamene di Barletta. Archivio Capitolare (8971285), Codice diplomatico barese, VIII. Bari (abbreviato CDB VIII).

PREDELLI, Riccardo. 1876. I libri commemoriali della Republica di Venezia: regesti, I. Venezia.

PRESSUTTI, Pietro. 1985. Regesta Honorii Papae III, t. 2. Romae.

SCHOTTMÜLLER, Konrad. 1887. Der Untergang des Templer Ordens, II. Berlin.

SMIČIKLAS, Tadija. 1904-1910. Codex diplomaticus regni Croatiae, Dalmatiae et Slavoniae. Zagreb (abbreviato in $\mathrm{CD}$ ). 
THEINER, Augustinus. 1863. Vetera Slavorum Meridionalium historia illustrantia, I. Romae.

Thomas Archidiaconus Spalatensis 2006: Historia Salonitanorum atque Spalatinorum pontificum, eds. Olga Perić, Damir Karbić, Mirjana Matijević Sokol, James Ross Sweeney. Budapest.

WENZEL, Gusztáv. 1869. Codex diplomaticus Arpadianus continuatus, VII. Pest.

WENZEL, Gusztáv. 1874. Monumenta Hungariae historica Acta extera, I. Budapest.

\section{Letteratura}

ALACEVICH, Angelico. 1889-1891. Il monastero e la chiesa dei SS. Cosma e Damiano sull'isola di Pasmano. Bulletino di archeologia e storia Dalmata XI: 139-141; XII: 25-27, 40-41, 186-189; XIII: 13-15, 26-30, 41-44, 61-63, 76-78, 93-95, 110-111, 183 187; XIV: 28-32, 38-43, 57-59, 74-77.

BARBER, Malcolm. 1994. The New Knighthood. A History of the Order of the Temple. Cambridge.

BARTULOVIĆ, Željko. 2007. Neka pitanja iz povijesti Senja [Some questions about the history of Senj]. Senjski zbornik 34, 265-296.

BELLOMO, Elena. 2007. The Templar Order in North-west Italy (1142-c. 1330). Leiden.

BELLOMO, Elena. 2012. Templari, Oriente, Crociata: percorsi di ricerca in Italia settentrionale. In As Ordens Militares. Freires, Guerreiros, Cavaleiros. Actas do VI Encontro sobre Ordens Militares, Isabel Cristina Ferreira Fernandes (dir.), II, 799-822. Palmela.

BIANCHI, Carlo Federico. 1880. Zara Cristiana, II. Zara.

BOMMAN, Gianantonio. 1775. Storia civile ed ecclesiastica della Dalmazia Croazia e Bosna, II. Venezia.

BORCHARDT, Karl. 2013. The Templars and Thirteenth-Century Colonisation in Eastern Central Europe. In L'économie templière en Occident: patrimoines, commerce, finances. Actes du colloque international (Troyes-Abbaye de Clairvaux, 24-26 octobre 2012), Arnaud Baudin, Ghislain Brunel, Nicolas Dohrmann (dir.), 419-456. Reims.

BOROVICZÉNY, Károly György. 1991. Cruciferi Sancti Regis Stephani. Tanulmányok a stefaniták, egy középkori magyar ispotályos rend történetéből [Study from the History of a Medieval Hungarian Hospitaller Order: the Stephanites]. Orvostörténeti Közlemények. Communicationes de Historiae Artis Medicinae 23-24, 133-140, 7-48.

BRAMATO, Fulvio. 1994. Storia dell'Ordine dei Templari in Italia. Le inquisizioni, le fonti. Roma.

BRUNELLI, Vitaliano. 1913. Storia della città di Zara. Venezia.

CAPASSO, Bartolomeo. 1869. Sulla storia esterna delle Costituzioni del Regno di Sicilia promulgate da Federico II. Napoli.

CAPONE, Bianca. 1997. Quando in Italia c'erano i Templari. Italia settentrionale. Torino.

CAPONE, Bianca, Loredana IMPERIO. 1993. I cavalieri templari della nobile famiglia de Canellis. In Atti del X Convegno di Ricerche templari Poggibonsi (Si), 12-13 settembre 1992, ed. Libera Associazione Ricercatori Templari Italiani, 45-58. Tuscania. 
CARABELLESE, Francesco. 1911. Carlo d'Angiò nei rapporti politici e commerciali con Venezia e l'Oriente. Bari.

CARRAZ, Damien. 2009. Christi fideliter militantium in subsidio Terre Sancte. Les ordres militaires et la première maison d'Anjou (1246-1342). In As Ordens Militares e as Ordens de Cavalaria entre o Ocidente e o Oriente. Actas do V Encontro sobre Ordens Militares, Palmela, 15 a 18 de fevereiro de 2006, Isabel Cristina Ferreira Fernandes (dir.), 549-582. Palmela.

CARRAZ, Damien. 2010. Pro servitio maiestatis nostre. Templiers et hospitaliers au service de la diplomatie de Charles Ier et Charles II. In La diplomatie des États Angevins aux XIIIe et XIVe siècles. Actes du colloque international de Szeged, Visegrad, Budapest 13-16 septembre 2007, Zoltan Kordé, Istvan Petrovics (dir.), 21-42. Roma-Szeged.

CATTALINICH, Giovanni. 1834. Storia della Dalmazia, II. Zara.

CLAVERIE, Pierre-Vincent. 2009. Guerre de Saint Sabas. In Prier et combattre: dictionnaire europeen des ordres militaires au Moyan Age, N. Beriou, Ph. Josserand (dir.), 408-409. Paris.

CSUKOVITS, Enikö. 2013. L'Ungheria angioina. Roma.

DE BENVENUTI, Angelo. 1940. Il castello di Vrana. La rivista Dalmatica XXI/1: 49-54.

DE CURZON, Henry. 1888. La maison de Temple de Paris. Historie et description. Paris.

DEMURGER, Alain. 2004. Tramonto e fine dei cavalieri templari. Roma.

DEMURGER, Alain. 2009. I Templari. Un Ordine cavalleresco cristiano nel Medioevo. Milano.

DE REGIBUS, Adalgisio. 1934. Le contese degli angioini di Napoli per il trono di Ungheria: 1290-1310. Pinerolo.

DI VITTORIO, Antonio. 1994. Ragusa (Dubrovnik) una repubblica adriatica. Saggi di storia economica e finanziaria. Bologna.

DOBRONIĆ, Lelja. 1984a. Viteški redovi. Templari i ivanovci u Hrvatskoj [Gli Ordini militari. Templari e Ospitalieri in Croazia]. Zagreb.

DOBRONIĆ, Lelja. 1984b. Posjedi i sjedišta templara, ivanovaca i sepulkralaca u Hrvatskoj [Proprietà e insediamenti templari, ospitalieri e del Santo Sepolcro in Croazia]. Zagreb.

DOBRONIĆ, Lelja. 1986. The military orders in Croatia. In The meeting of two worlds: cultural exchange between East and West during the period of the crusades, ed. Vladimir Goss, 431-438. Kalamazoo Michigan.

DOBRONIĆ, Lelja. 2003. Templari u Senju [I Templari a Segna]. Senjski zbornik XXX/1: 191-200.

DUPLANČIĆ, Arsen. 2008. Pečat splitskog i šibenskog kneza Domalda [A Seal of Prince Domald of Split and Šibenik]. Archaeologia Adriatica 11: 243-249.

FEKETE NAGY, Antonio. 1927. La politica marittima dei re d'Ungheria e il commercio delle città dalmate sino al regno di Carlo Roberto d'Angiò. Corvina, Rivista di scienze, lettere ed arti della Società ungherese-italiana Mattia Corvino 13-14: 66-90.

FERRARI-CUPILLI, Giuseppe. 1889. I Templari e gli Ospitalieri in Dalmazia. In Dalmazia in Scritti storici e letterari, ed. Giuseppe Ferrari-Cupilli, I, 171-196. Zara. 
FOREY, Alan John. 1997. Templari. In Dizionario degli istituti di perfezione, vol. 9, 886-896. Roma.

FORTIS, Alberto. 1774. Viaggio in Dalmazia, I. Venezia.

FRESCHOT, Casimiro. 1687. Memorie historiche, e geografiche della Dalmazia raccolte da d. Casimiro Freschot. Bologna.

GILMOUR-BRYSON, Anne. 1982. The trial of the Templars in the Papal State and the Abruzzi. Città del Vaticano.

GILMOUR-BRYSON, Anne. 1998. The Trial of the Templars in Cyprus. Leiden.

GRAČANIN, Hrvoje. 2011. Ivan Paližna u povijesnim vrelima i historiografiji [Ivan Paližna in Historical Sources and Historiography]. Radovi Zavoda za znanstvenoistraživački i umjetnički rad u Bjelovaru 4: 237-267.

GRAČANIN, Hrvoje, Igor RAZUM. 2012. Toma Arhiđakon i križarstvo [Thomas the Archdeacon and the Crusades]. Povijest u nastavi 10-1 (19): 45-64.

GUSAR Karla, Dario VUJEVIĆ. 2013. Grob 75 s lokaliteta Pakoštane-Crkvina [Grave 75 at the Pakoštane-Crkvina site]. Archaeologia Adriatica 7: 271-300.

GUZZO, Cristian. 2003. Templari in Sicilia. La storia e le sue fonti tra Federico II e Roberto d'Angiò. Genova.

HÒMAN, Bàlint. 1938. Gli Angioini di Napoli in Ungheria 1290-1403. Roma.

HUNYADI, Zsolt. 2003. Milites Christi in the Medieval Kingdom of Hungary: a historiographical overview. Cronica 3: 50-57.

HUNYADI, Zsolt. 2008. Hospitaller Commanderies in the Kingodom of Hungary (c. 1150-c. 1330). In The Military Orders. History and Heritage, 3, ed. Victor MalliaMilanes, 257-268. Aldershot.

HUNYADI, Zsolt. 2011. The formation of the territorial structure of the Templars and Hospitallers in the medieval Kingdom of Hungary. In Die geistlichen Ritterorden in Mitteleuropa. Mittelalter, eds. Karl Borchardt, Jan Libor, 183-197. Brno.

KARBIĆ, Damir. 1999. The Šubići of Bribir. A Case Study of a Croatian Medieval Kindred (unpublished $\mathrm{Ph}$. D. Thesis). Budapest.

KARBIĆ, Damir. 2001. Uloga bribirskih knezova u osnutku Šibenske biskupije [The Role of the Counts of Bribir in the establishment of the bishopric of Šibenik]. In Sedam stoljeća šibenske biskupije, ed. Vilijam Lakić, 53-62. Šibenik.

KARBIĆ, Damir. 2005. Šubići Bribirski do gubitka nasljedne banske časti (1322.) [The Šubići of Bribir until the Loss of the Hereditary Position of the Croatian Ban (1322)]. Zbornik Odsjeka za povijesne znanosti Zavoda za povijesne i društvene znanosti Hrvatske akademije znanosti i umjetnosti 22: 1-26.

KARBIĆ, Damir. 2010. Diplomacy of the Subici Regarding Relations between Neapolitan Angevins, the Papacy and Venice at the End of the Thirteenth and in the First Decades of the Fourteenth Century. In La diplomatie des états angevins aux XIII et XIV. Siècles. Actes du colloque International de Szeged, Visegrad, Budapest 13-16 septembre 2007, Zoltan Kordé, Istvan Petrovics (dir.), 125-140. Roma-Szeged.

KLANICZAY, Gabor. 2002. Angevins of Hungary. In Encyclopedia of the Middle Ages, ed. André Vauchez. Oxford. 
KOLANOVIĆ, Josip. 1971. Vrana i Templari [I Templari e Vrana]. Radovi Istraživačkog centra Jugoslavenske akademije znanosti i umjetnosti u Zadru 18: 207-226.

KOS, Lucijan. 1971. Prior vranski i njegove funkcije u našoj pravnoj povijesti [The prior of Vrana and his function in the Croatian legal practice]. Radovi Istraživačkog centra Jugoslavenske akademije znanosti i umjetnosti u Zadru 18: 227-237.

KOSI, Miha. 1995. Templarji na Slovenskem [I Templari in Slovenia]. Ljubljana.

KOSI, Miha. 2001. The Ages of the Crusades in the South-East of the Empire (Between the Alps and the Adriatic). In The Crusades and the Military Orders: ding the Frontiers of Medieval Latin Christianity, The Military Orders. On land and by sea, 4, eds. Zsolt Hunyadi, József Laszlovszky, 123-165. Budapest.

KREKIC, Barisa. 1962. La Puglia tra Dubrovnik (Ragusa) e il Levante nell'epoca angioina. In Per una storia delle relazioni tra le due sponde adriatiche, ed. Società di Storia Patria per la Puglia, 63-69. Bari.

KUKULJEVIĆ SAKCINSKI, Ivan. 1886. Priorat Vranski sa Vitezi Templari i Hospitalci Sv. Ivana u Hrvatskoj [Il priorato di Vrana dei cavalieri templari ed ospitalieri di San Giovanni in Croazia]. Zagreb.

LAGO, Valentino. 1869. Memorie sulla Dalmazia, I. Venezia.

LAGO, Valentino. 1870. Memorie sulla Dalmazia, II. Venezia.

LICINIO, Raffaele. 1994. Castelli medievali: Puglia e Basilicata, dai Normanni a Federico II e Carlo I d'Angiò. Bari.

MARGETIĆ, Lujo. 2007. Senjski statut iz godine 1388 [Lo Statuto di Segna del 1388]. Senjski zbornik XII/14 (1): 10-99.

MATIĆ, Tomislav. 2009. Balkanski križonoše: ekonomska i politička uloga templara na hrvatskom prostoru [I Cruciferi dei Balcani: il ruolo economico e politico dei Templari in Croazia]. Radovi Zavoda za hrvatsku povijest Filozofskoga fakulteta Sveučilišta u Zagrebu 41: 367-394.

MOGOROVIĆ CRLJENKO, Marija. 2002. Hospitali u Istri u srednjem i ranom novom vijeku [Charitable institutions in Istria during the medieval and the early modern ages]. Povijesni prilozi 23: 105-116.

PACINI, Gian Piero. 2002. I Crociferi e le comunità ospedaliere lungo le vie dei pellegrinaggi nel veneto medioevale secoli XII-XIV. In I percorsi della fede e l'esperienza della carità nel Veneto medioevale: atti del convegno, Castello di Monselice, 28 maggio 2000, ed. A. Rigon, 155-172. Padova.

PERIČIĆ, Eduard. 1971. Vranski priori Ivan od Paližne i Petar Berislavić [John of Palisna and Peter Berislo, Hospitaller Priors of Vrana]. Radovi Istraživačkog centra Jugoslavenske akademije znanosti i umjetnosti u Zadru 18: 239-321.

PETROVIĆ, Mišo. 2016. Papal power, local communities and pretenders: the Church of Croatia, Dalmatia and Slavonia and the struggle for the throne of the Kingdom of Hungary-Croatia (1290-1301). Banatica 26: 11-31.

PEZZELLA, Nicola. 2002. Un insediamento templare "di stato": Santa Maria in Broglio di Venezia. In Atti del XX convegno di ricerche templari, Barletta 7-8 settembre 2002, ed. Libera Associazione Ricercatori Templari Italiani, 53-68. Latina. 
PEZZELLA, Nicola. 2004. I templari nell'Istria e nel Carso sloveno. In Atti del XXI convegno di ricerche templari, Savona 7-8 settembre 2003, ed. Libera Associazione Ricercatori Templari, 73-83. Latina.

PHILLIPS, Jonathan. 2009. Sacri guerrieri. La straordinaria storia della Crociate. Bari-Roma.

POPOVIĆ-RADENKOVIC, Miriana. 1958. Ragusa e la Puglia nel periodo angioino (1266-1442). Archivio Storico per le Province Napoletane 37: 73-104, 153-206.

RICCI, Vito. 2014. Gli Ordini religioso-militari e i porti pugliesi. In Atti del XXXI convegno di ricerche templari, Bologna 12 ottobre 2013, ed. Libera Associazione Ricercatori Templari Italiani, 51-108. Tuscania.

RICCI, Vito. 2016. I Maestri della Provincia templare di Ungheria. In Atti del XXXIII convegno di ricerche templari, Vicenza 19 settembre 2015, ed. Libera Associazione Ricercatori Templari Italiani, 123-149. Tuscania.

RICCI, Vito. 2017. Province e maestri provinciali templari nel Mezzogiorno Italiano. Taranto.

SIRE, Hja. 2008. The Priory of Vrana: The Order of St. John in Croatia. In The Military Orders. On land and by sea, 4, ed. Judith Upton-Ward, 221-228. Aldershot.

STOPANI, Renato. 2006. La Francigena dei Balcani. La "via diagonalis", itinerario terrestre per Gerusalemme. De strata francigena XIV/1: 9-16.

STOSSEK, Balázs. 2001. Maisons and Possessions des Templiers en Hongrie, In The Crusades and the Military Orders: ding the Frontiers of Medieval Latin Christianity, The Military Orders. On land and by sea, 4, eds. Zsolt Hunyadi, József Laszlovszky, 245-251. Budapest.

TADIĆ, Joryo. 1960. La Puglia e le città dalmate nei secoli XII-XIII. Archivio Storico Pugliese 13: 187-191.

TOOMASPOEG, Kristjan. 2011. Les Ordres religieux militaires et la diplomatie. Formes et enjeux. In Les relations diplomatiques au Moyen Ages. Formes et enjeux, 227-238. Paris.

TOOMASPOEG, Kristjan. 2012a. Gli insediamenti templari, giovanniti e teutonici nell'economia della Capitanata medievale. In Federico II e i cavalieri teutonici in Capitanata. Recenti ricerche storiche e archeologiche. Atti del Convegno internazionale (Foggia-Lucera-Pietra Montecorvino, 10-13 giugno 2009) [Acta Theutonica 7], 183-214. Galatina.

TOOMASPOEG, Kristjan. 2012b. Charles Ier d'Anjou, les Ordres militaires et la Terre Sainte. In As Ordens Militares. Freires, Guerreiros, Cavaleiros. Actas do VI Encontro sobre Ordens Militares, Vol. 2, GEsOS / Município de Palmela, Isabel Cristina Ferreira Fernandes (Coord.), 761-777. Palmela.

VANNI, Fabrizio. 2006. Le vie terrestri dei Balcani. Alcuni indizi di continuità nel tempo. De strata francigena XIV/1: 17-27.

ZANINOVIĆ, Joško. 1993. Ivanovci (malteški vitezovi) na tlu Hrvatske do 1526. godine (povijesni pregled) [Gli Ospitalieri (cavalieri di Malta) in terra croata sino al 1526 (sintesi storica)]. Croatica Christiana Periodica XXVII/31: 25-41.

ZELIĆ, Danko. 1999. Templarski castrum u Šibeniku [Il castrum templare di Sebenico]. Radovi Instituta za povijest umjetnosti 23: 33-42. 


\section{Templar Settlements in Istria and along the Croatian Coast and Relations with Western Adriatic Side}

The presence of Templars in Croatian territory in general, and in Dalmatia and Istria in particular, is due to its role as a transit area on the route to the Holy Land, both by sea and by land. Their settlements in coastal towns, primarily the port of Senj, were very important because of their connections with Italian towns on the other side of the Adriatic. Templars were particularly favoured by the kings of Hungary-Croatia, which took the Order under their protection and issued a great number of donations pertaining not only to lands, but entire fiefs or towns. On the other hand, the Templars were always reliable and trusted men in the service of both the Árpád and Angevin rulers. One of the most important Templar centres in Croatia was the domus of Vrana, a Benedictine monastery converted into a fortress by the knights. Unfortunately, relations between the Templars and the inhabitants of the centres in which they settled and got in fief were not always good. One just has to recall the difficulties they encountered in Senj, Klis and Šibenik, forcing the Order to abandon these places with heavy economic loss, particularly due to the loss of Senj that provided considerable revenue from the rights pertaining to the ships calling in the port. The overview of Templar presence on the eastern Adriatic coast in Istria, Croatia and Dalmatia is followed by the analysis of the relations between the two sides of the Adriatic involving Templars, which is divided in three groups of questions. The first one includes economic and trading relations or exchanges such as the shipping of wheat from Apulia to Zadar, or the shipment of legumes in the province of Hungary, or freighting of Dalmatian ships by Templars to Apulia. The second group concerns relations between Croatian and Istrian Templar settlements and the Republic of Venice; while the third one takes into consideration relations with regard to Templar knights' international mobility and their changing tasks in the Order and diplomatic missions, mostly after the accession of the Angevin dynasty, rulers of southern Italy, to the throne of the Kingdom of Hungary-Croatia.

\section{Templarske naseobine u Istri i na hrvatskoj obali i odnosi sa zapadnojadranskom stranom}

Nazočnost templara na hrvatskom tlu općenito, a u Dalmaciji i Istri napose, posljedica je uloge koju je ovo područje igralo kao tranzitna zona prema Svetoj zemlji kako morem, tako i kopnom. Vrlo su važne bile templarske naseobine u obalnim gradovima, prvenstveno u luci Senj, zbog veza s talijanskim gradovima na Jadranu. Naročito nakloni templarima bili su ugarsko-hrvatski kraljevi koji su 
Red uzeli pod svoju zaštitu i dodijelili mu mnoge velike donacije, i to ne samo zemlju nego i čitave gradove u feud. Sa svoje strane, templari su uvijek bili pouzdanici kako dinastije Arpadovića, tako i dinastije Anžuvinaca. Jedan od najvažnijih templarskih središta u Hrvatskoj bio je domus u Vrani, benediktinskom samostanu koji su vitezovi pretvorili u tvrđavu. Nažalost, odnosi između templara i stanovnika središta u kojima su se smjestili i koja su dobili kao feud nisu uvijek bili dobri. Samo se treba sjetiti poteškoća na koje su nailazili u Senju, Klisu i Šibeniku, a natjerale su Red da napusti ta mjesta uz tešku gospodarsku štetu, naročito uslijed gubitka Senja koji je davao znatan prihod na temelju prava da brodovi pristanu u luci. Nakon pregleda templarske nazočnosti na istočnoj jadranskoj obali u Istri, Hrvatskoj i Dalmaciji, proučavaju se odnosi između dviju strana Jadranskog mora u vezi s templarima prema trima skupinama pitanja. Prva uključuje ekonomske i trgovinske odnose, odnosno razmjenu poput dopreme pšenice iz Apulije u Zadar ili dopreme mahunarki u ugarsku provinciju, odnosno templarski prijevoz dalmatinskih brodova u Apuliju. Druga skupina tiče se odnosa između templarskih naselja u Hrvatskoj i Istri te Mletačke Republike; posljednja, pak, skupina razmatra odnose u vezi s međunarodnom mobilnošću vitezova templara i njihovim promjenljivim zadaćama u Redu i diplomatskim misijama uglavnom nakon uspona anžuvinske dinastije, koja je vladala u južnoj Italiji, u Ugarsko-Hrvatskom Kraljevstvu.

Keywords: Templars, Medieval Croatia, Adriatic Sea, Kingdom of Hungary-Croatia. Parole chiave: Templari, Croazia medievale, Adriatico, Regno di Ungheria-Croazia. Kjučne riječi: Capital initial for Templari, srednjovjekovna Hrvatska, Jadran, Ugarsko-Hrvatsko Kraljevstvo.

Vito Ricci

Università degli studi di Bari Aldo Moro

Via Isonzo 9370125 Bari

vito.ricci@uniba.it 


\section{FILOZOFSKI FAKULTET SVEUČILIŠTA U ZAGREBU \\ ZAVOD ZA HRVATSKU POVIJEST \\ INSTITUTE OF CROATIAN HISTORY \\ INSTITUT FÜR KROATISCHE GESCHICHTE}

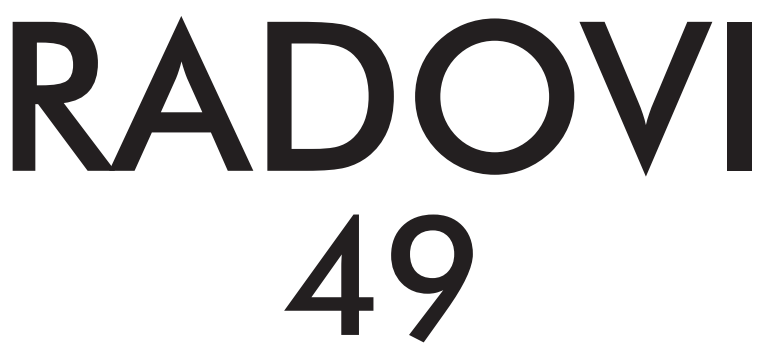

ZAVOD ZA HRVATSKU POVIJEST

FILOZOFSKOGA FAKULTETA SVEUČILIŠTA U ZAGREBU

\section{FF press}

ZAGREB 2017. 


\title{
RADOVI ZAVODA ZA HRVATSKU POVIJEST FILOZOFSKOGA FAKULTETA SVEUČILIŠTA U ZAGREBU \\ Knjiga 49
}

\author{
Izdavač / Publisher \\ Zavod za hrvatsku povijest \\ Filozofskoga fakulteta Sveučilišta u Zagrebu \\ FF-press \\ Za izdavača / For Publisher \\ Vesna Vlahović Štetić \\ Glavni urednik / Editor-in-Chief \\ Hrvoje Gračanin \\ Izvršna urednica / Executive Editor \\ Inga Vilogorac Brčić \\ Uredništvo / Editorial Board
}

Bruna Kuntić-Makvić (stara povijest/ancient history), Zrinka Nikolić Jakus (srednji vijek/

medieval history), Hrvoje Petrić (rani novi vijek/early modern history), Željko Holjevac (moderna povijest/modern history), Tvrtko Jakovina (suvremena povijest/contemporary history),

Silvija Pisk (mikrohistorija i zavičajna povijest/microhistory and local history),

Zrinka Blažević (teorija i metodologija povijesti/theory and methodology of history)

Međunarodno uredničko vijeće / International Editorial Council

Denis Alimov (Sankt Peterburg), Živko Andrijašević (Nikšić), Csaba Békés (Budapest), Rajko Bratož (Ljubljana), Snježana Buzov (Columbus, Ohio), Svetlozar Eldarov (Sofija), Toni Filiposki

(Skopje), Aleksandar Fotić (Beograd), Vladan Gavrilović (Novi Sad), Alojz Ivanišević (Wien),

Egidio Ivetić (Padova), Husnija Kamberović (Sarajevo), Karl Kaser (Graz),

Irina Ognyanova (Sofija), Géza Pálffy (Budapest), Ioan-Aurel Pop (Cluj),

Nade Proeva (Skopje), Alexios Savvides (Kalamata), Vlada Stanković (Beograd),

Ludwig Steindorff (Kiel), Peter Štih (Ljubljana)

Izvršni urednik za tuzemnu i inozemnu razmjenu /

Executive Editor for Publications Exchange

Martin Previšić

Tajnik uredništva / Editorial Board Assistant

Dejan Zadro

Adresa uredništva/Editorial Board address

Zavod za hrvatsku povijest, Filozofski fakultet Zagreb, Ivana Lučića 3, HR-10 000, Zagreb

Tel. ++385 (0)1 6120 150, 6120 158, faks ++385 (0)1 6156879

Časopis izlazi jedanput godišnje / The Journal is published once a year

Časopis je u digitalnom obliku dostupan na / The Journal in digital form is accessible at

Portal znanstvenih časopisa Republike Hrvatske „Hrčak“ http://hrcak.srce.hr/radovi-zhp

Financijska potpora za tisak časopisa / The Journal is published with the support by Ministarstvo znanosti, obrazovanja i športa Republike Hrvatske

Časopis je indeksiran u sljedećim bazama / The Journal is indexed in the following databases: Directory of Open Access Journals, EBSCO, SCOPUS, ERIH PLUS, Emerging Sources Citation Index - Web of Science 


\title{
Naslovna stranica / Title page by
}

Iva Mandić

\section{Grafičko oblikovanje i računalni slog / Graphic design and layout Marko Maraković}

\author{
Lektura / Language editors \\ Samanta Paronić (hrvatski / Croatian) \\ Dražen Nemet (engleski / English) \\ Tisak / Printed by \\ Tiskara Zelina d. d., Sveti Ivan Zelina \\ Naklada / Issued \\ 250 primjeraka / 250 copies
}

Časopis je u digitalnom obliku dostupan na Portalu znanstvenih časopisa Republike Hrvatske „Hrčak“ http://hrcak.srce.hr/radovi-zhp

The Journal is accessible in digital form at the Hrcak-Portal of scientific journals of Croatia http://hrcak.srce.hr/radovi-zhp 